Yasutomo Murasawa*

\title{
Bayesian multivariate Beveridge-Nelson decomposition of I(1) and I(2) series with cointegration
}

\author{
https://doi.org/10.1515/snde-2020-0049
}

Received April 27, 2020; accepted April 27, 2021; published online June 2, 2021

\begin{abstract}
The dynamic IS equation implies that if the real interest rate is I(1), then so is the output growth rate with possible cointegration, and log output is I(2). This paper extends the Beveridge-Nelson decomposition to such a case, and develops a Bayesian method to obtain error bands. The method is valid whether log output is I(1) or I(2). The paper applies the method to US data to estimate the natural rates (or their permanent components) and gaps of output, inflation, interest, and unemployment jointly, and finds that allowing for cointegration gives much bigger estimates of the gaps for all variables.
\end{abstract}

Keywords: natural rate; output gap; trend-cycle decomposition; trend inflation; unit root; vector error correction model (VECM).

\section{Introduction}

Distinguishing between growth and cycles is fundamental in macroeconomics. One can define growth as the time-varying steady state, or the permanent component, and cycles as deviations from the steady state, or the transitory component. One may interpret the permanent and transitory components as the natural rate and gap, respectively, though some economists may disagree with such interpretation, in which case one can consider the permanent component of the natural rate. ${ }^{1}$ If shocks affecting the two components differ, then policy prescriptions for promoting growth and stabilizing cycles differ. Thus it is useful to decompose economic fluctuations into the two components.

Among such decomposition methods, this paper focuses on the multivariate Beveridge-Nelson (B-N) decomposition, which decomposes a multivariate $\mathrm{I}(1)$ or $\mathrm{CI}(1,1)$ series into a random walk permanent component and an $\mathrm{I}(0)$ transitory component, assuming a linear time series model such as a VAR model or a vector error-correction model (VECM) for the differenced series. In practice, however, some series may be I(2), e.g., log output in some countries, in which case one must decompose I(1) and I(2) series jointly. Murasawa (2015) develops the multivariate $\mathrm{B}-\mathrm{N}$ decomposition of $\mathrm{I}(1)$ and $\mathrm{I}(2)$ series.

As Murasawa (2015) shows, for non-US data, the B-N decomposition assuming I(1) log output often gives an unreasonable estimate of the output gap, perhaps because of possible structural breaks in the mean output growth rate; see Figure 1. Kamber, Morley, and Wong (2018, p. 563) explain,

1 Phelps (1995) defines the natural rate as the current stationary rate (p. 16) or the equilibrium steady state path (pp. 29-30). Woodford (2003, pp. 8-9) defines the natural rate as the equilibrium rate under flexible prices, which may not be in the steady state. Kiley (2013) compares alternative definitions empirically using a new Keynesian DSGE model for the US, and obtains similar estimates of the output gap. Laubach and Williams (2016) and Holston et al. (2017) note that these long-run and short-run views are complementary. Del Negro et al. (2017) also distinguish the natural rate and its low-frequency component. See also Glick (2020, sec. 2.2) for alternative definitions of the natural rate of interest $r^{*}$.

*Corresponding author: Yasutomo Murasawa, Faculty of Economics, Konan University, 8-9-1 Okamoto, Higashinada-ku, Kobe, Hyogo 658-8501, Japan, E-mail: yasutomo.murasawa@gmail.com. https://orcid.org/0000-0001-6716-0162 


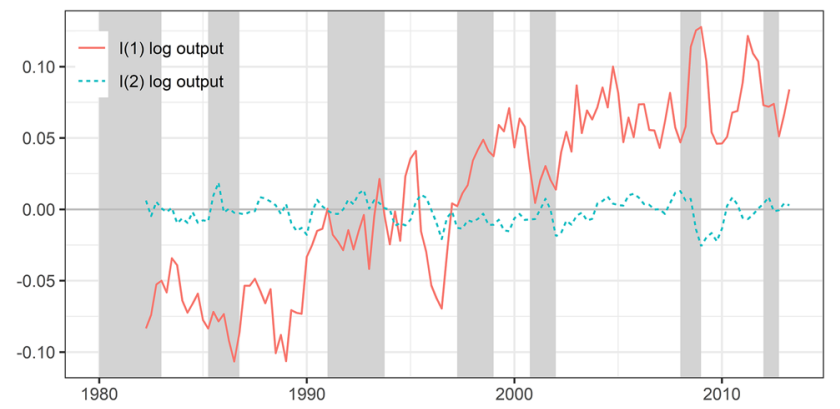

Figure 1: Output gap estimates in Japan given by the multivariate $\mathrm{B}-\mathrm{N}$ decomposition assuming I(1) or I(2) log output. The plots replicate those in Murasawa (2015, Figures 2 and 3). The shaded areas indicate the recessions determined by the Cabinet Office.

... if there is a large reduction in the long-run growth rate, a forecasting model that fails to account for it will keep anticipating faster growth than actually occurs after the break, leading to a persistently negative estimate of the output gap based on the BN decomposition. ${ }^{2}$

Assuming I(2) log output and hence I(1) output growth rate, one introduces a stochastic trend in the output growth rate, which captures possible structural breaks in the mean growth rate automatically in real time without specifying break dates a priori. Thus the B-N decomposition assuming I(2) log output gives a more 'reasonable' estimate of the output gap that fluctuates around 0; see Figure 1.

This paper extends Murasawa (2015) in two ways. First, we allow for cointegration in the multivariate B-N decomposition of I(1) and I(2) series. Recall that the consumption Euler equation in a simple macroeconomic model implies a dynamic IS equation such that for all $t$,

$$
\mathrm{E}_{t}\left(\Delta \ln Y_{t+1}\right)=\frac{1}{\sigma}\left(r_{t}-\rho\right)
$$

where $Y_{t}$ is output, $r_{t}$ is the real interest rate, $\rho$ is the discount rate, and $\sigma$ is the curvature of the utility of consumption; see Gali (2015, pp. 21-23). This equation implies that if $0<\sigma<\infty$, then the output growth rate and the real interest rate are of the same order of integration; thus if the real interest rate is I(1), then so is the output growth rate with possible cointegration, and log output is I(2). This observation motivates our development of the multivariate B-N decomposition of I(1) and I(2) series with cointegration. . $^{3}$

Second, we apply Bayesian analysis to obtain error bands for the components, building on recent developments in Bayesian analysis of a VECM. Since cointegrating vectors require normalization, our parameter of interest is in fact the cointegrating space rather than cointegrating vectors. Strachan and Inder (2004) use a matrix angular central Gaussian (MACG) distribution proposed by Chikuse (1990) as a prior on the cointegrating space. Koop, León-González, and Strachan (2010) propose two Gibbs samplers, a collapsed Gibbs sampler and a parameter-augmented Gibbs sampler, for posterior simulation of such a model. Since one often has prior information on the steady state of a system, Villani (2009) specifies a prior on the steady state form of a VECM. Since some hyperparameters such as the tightness (shrinkage) hyperparameter on the

2 In this quote, Kamber et al. (2018) seem to consider the output growth rate gap. If one fails to account for a large reduction in the true mean growth rate $\mu^{*}$, then the output growth rate $\Delta \ln Y_{t}$ tends to be below the assumed mean growth rate $\mu$; i.e., the output growth rate gap $\Delta \ln Y_{t}-\mu$ indeed tends to be negative. If $\log$ output is I(1), so that the output growth rate is I(0), then with positive serial correlation, the future $\Delta \ln Y_{t}-\mu$ tends to be negative, implying that the current output gap is positive, as shown in Figure 1.

3 Since the B-N decomposition requires only a reduced-form forecasting model, we do not assume Eq. (1), which is just a motivating example for considering some cointegration. Though we assume that $\left\{\Delta \ln Y_{t}\right\}$ is I(1), our method is valid even if it is $\mathrm{I}(0)$, since we can treat an $\mathrm{I}(0)$ series as an $\mathrm{I}(1)$ series cointegrated with itself, i.e., 'pseudo' cointegration; see Fisher et al. (2016, section 2.2).

4 One can think of this paper as a reduced-form VECM version of Laubach and Williams (2003), though we include more variables. To estimate the natural rate of interest, they start from the consumption Euler equation, and assume I(2) log output. In one specification, they also assume cointegration between the output growth rate and the real interest rate. 
VAR coefficients are difficult to choose, Giannone, Lenza, and Primiceri (2015) use a hierarchical prior. Using these ideas, we develop a Gibbs sampler to simulate the joint posterior distribution of the components. ${ }^{5}$

As an application, we simulate the joint posterior distribution of the natural rates (or their permanent components) and gaps of output, inflation, interest, and unemployment in the US during 1950Q1-2018Q4. To apply the Bayesian multivariate B-N decomposition of $\mathrm{I}(1)$ and $\mathrm{I}(2)$ series with cointegration, we assume a four-variate VAR model for the output growth rate, the CPI inflation rate, the short-term interest rate, and the unemployment rate, and estimate it in the VECM form. The Bayes factors give decisive evidences that the cointegrating rank is 2 . The posterior medians of the gaps seem reasonable compared to previous works that focus on a particular natural rate or gap. The posterior probability of positive gap is useful when the sign of the gap is uncertain. The Phillips curve and Okun's law hold between the gaps despite that we do not impose such relations. The dynamic IS equation holds between the natural rates of output and interest, though the evidence is weak. Comparisons of alternative model specifications show not only that assuming I(2) log output gives a more 'reasonable' estimate of the output gap, but also that allowing for cointegration gives much bigger estimates of the gaps for all variables.

The paper proceeds as follows. Section 2 reviews the literature on the B-N decomposition. Section 3 derives the multivariate $\mathrm{B}-\mathrm{N}$ decomposition of $\mathrm{I}(1)$ and $\mathrm{I}(2)$ series with cointegration. Section 4 specifies our model and prior, and explains our posterior simulation and model evaluation. Section 5 applies the method to US data. Section 6 discusses remaining issues. The Appendix gives the details of the derivation of our algorithm. We use the notation proposed by Abadir and Magnus (2002).

\section{Literature}

Beveridge and Nelson (1981) give operational definitions of the permanent and transitory components, show that one can express any I(1) series as the sum of a random walk permanent component and an I(0) transitory component, and propose the B-N decomposition of a univariate I(1) series, assuming an ARIMA model. ${ }^{6}$

Multivariate extension of the B-N decomposition is straightforward. Evans (1989a, 1989b) and Evans and Reichlin (1994) apply the B-N decomposition to a multivariate series consisting of I(0) and I(1) series, assuming a VAR model for the stationarized series. Evans and Reichlin (1994) show that the transitory components are no smaller with the multivariate B-N decomposition than with the univariate one. This is because the transitory components are 'forecastable movements' (Rotemberg and Woodford 1996), and multivariate models forecast no worse than univariate models, using more information. King et al. (1991) and Cochrane (1994) apply the B-N decomposition to a CI(1,1) series, assuming a VECM.

Morley (2002) gives a general framework for the $\mathrm{B}-\mathrm{N}$ decomposition, using a state space representation of the assumed linear time series model. Garratt, Robertson, and Wright (2006) note that if the state vector is observable as in a VAR model or a VECM, then the transitory component is an explicit weighted sum of the observables given the model parameters; thus the multivariate B-N decomposition based on a VAR model or a VECM is transparent. They also note that the result of the multivariate $\mathrm{B}-\mathrm{N}$ decomposition depends strongly on the assumed cointegrating rank.

The B-N decomposition also applies to an I(2) series. Newbold and Vougas (1996), Oh and Zivot (2006), and Oh, Zivot, and Creal (2008) extend the B-N decomposition to a univariate I(2) series. Murasawa (2015) extends the method to a multivariate series consisting of I(1) and I(2) series.

One can apply Bayesian analysis to obtain error bands for the components. This approach is useful especially when the state vector is observable as in a VAR model or a VECM, in which case the components are

5 Since we assume a VECM as the true reduced-form model, the B-N decomposition defines the permanent and transitory components; hence it suffices for our error bands to reflect only parameter uncertainty. If we instead assume an unobserved components (UC) model as the true model, then the $\mathrm{B}-\mathrm{N}$ decomposition estimates the components, and we must consider estimation errors as well. See Morley (2011) on this distinction.

6 Beveridge and Nelson (1981) reverse the sign of the transitory component. Nelson (2008) explains why they had to do so. 
explicit functions of the model parameters and observables; thus the joint posterior distribution of the model parameters directly translates into that of the components. Murasawa (2014) uses a Bayesian VAR model to obtain error bands for the components.

Kiley (2013) uses a Bayesian DSGE model, but gives no error band for the components. Del Negro et al. (2017) use a Bayesian DSGE model and give error bands for the components. They also use a multivariate unobserved components (UC) model, where the permanent components have a factor structure and the transitory components follow a VAR model. Bayesian analysis of a UC model requires state smoothing, since the state vector is unobservable given the model parameters; thus it is less straightforward than that of a VAR model. Morley and Wong (2020) use a large Bayesian VAR model and give error bands for the components, but they do not take parameter uncertainty into account. ${ }^{7}$ There seems no previous work that uses a Bayesian VECM to obtain error bands for the components. ${ }^{8}$

\section{Model specification}

\subsection{VAR model}

Let for $d=1,2,\left\{\boldsymbol{x}_{t, d}\right\}$ be an $N_{d^{-}}$variate I $(d)$ sequence. Let $N:=N_{1}+N_{2}$. Let for all $t, \boldsymbol{x}_{t}:=\left(\boldsymbol{x}_{t, 1}^{\prime}, \boldsymbol{x}_{t, 2}^{\prime}\right)^{\prime}, \boldsymbol{y}_{t, 1}:=\boldsymbol{x}_{t, 1}$, $\boldsymbol{y}_{t, 2}:=\Delta \boldsymbol{x}_{t, 2}$, and $\boldsymbol{y}_{t}:=\left(\boldsymbol{y}_{t, 1}^{\prime}, \boldsymbol{y}_{t, 2}^{\prime}\right)^{\prime}$, where the prime (') denotes the transpose of a vector or a matrix, so that $\left\{\boldsymbol{y}_{t}\right\}$ is $\mathrm{I}(1)$. Assume also that $\left\{\boldsymbol{y}_{t}\right\}$ is $\mathrm{CI}(1,1)$ with cointegrating rank $r .{ }^{9}$ Let for $d=1,2, \boldsymbol{\mu}_{d}:=E\left(\Delta \boldsymbol{y}_{t, d}\right)$. Let $\boldsymbol{\mu}:=\left(\boldsymbol{\mu}_{1}^{\prime}, \boldsymbol{\mu}_{2}^{\prime}\right)^{\prime}$. Let $\left\{\boldsymbol{y}_{t}^{*}\right\}$ be such that for all $t$,

$$
y_{t}=\alpha+\mu t+y_{t}^{*}
$$

where $\boldsymbol{\alpha}$ is an intercept vector. Assume a $\operatorname{VAR}(p+1)$ model for $\left\{\boldsymbol{y}_{t}^{*}\right\}$ such that for all $t,{ }^{10}$

$$
\begin{aligned}
\Pi(\mathrm{L}) \boldsymbol{y}_{t}^{*} & =\boldsymbol{u}_{t} \\
\left\{\boldsymbol{u}_{t}\right\} & \sim \mathrm{WN}(\Sigma)
\end{aligned}
$$

where $\boldsymbol{\Pi}(\mathrm{L})$ is a $(p+1)$ th-order polynomial matrix in the lag operator L and $\mathrm{WN}(\Sigma)$ means '(multivariate) white noise sequence with variance-covariance matrix $\Sigma$ '.

\subsection{VECM representation}

Write

$$
\Pi(\mathrm{L})=\Pi(1) \mathrm{L}+\Phi(\mathrm{L})(1-\mathrm{L})
$$

7 Morley and Wong (2020) assume a UC model as the true model, and interpret the B-N decomposition as a way to estimate the components; hence their error bands reflect estimation errors of the components, but not parameter uncertainty.

8 Cogley et al. (2010) use a Bayesian time-varying parameter VAR model, which is a nonlinear time series model. They still apply the $\mathrm{B}-\mathrm{N}$ decomposition and give error bands for the components, pretending at each date that the VAR coefficients no longer vary. They justify their approach as an approximation based on an 'anticipated-utility' model. See also Cogley and Sargent (2002, 2005) and Cogley et al. (2005).

9 Our assumption includes the case where some series in $\left\{\boldsymbol{y}_{t}\right\}$ are $\mathrm{I}(0)$, since we can treat an $\mathrm{I}(0)$ series as an $\mathrm{I}(1)$ series cointegrated with itself, i.e., 'pseudo' cointegration; see Fisher, Huh, and Pagan (2016, section 2.2).

10 By starting from a VAR model for I(1) series $\left\{\boldsymbol{y}_{t}\right\}$, we exclude cointegration among I(2) series $\left\{\boldsymbol{x}_{t, 2}\right\}$ nor multicointegration (polynomial cointegration) studied by Johansen (1995), Granger and Lee (1989, 1990), and Gregoir and Laroque (1993, 1994). We leave extensions of our Bayesian multivariate $\mathrm{B}-\mathrm{N}$ decomposition to such cases for future work. 
where $\boldsymbol{\Phi}(\mathrm{L}):=(\boldsymbol{\Pi}(\mathrm{L})-\boldsymbol{\Pi}(1) \mathrm{L}) /(1-\mathrm{L})$. Then we have a VECM of order $p$ for $\left\{\Delta \boldsymbol{y}_{t}^{*}\right\}$ such that for all $t$,

$$
\begin{aligned}
\Phi(\mathrm{L}) \Delta y_{t}^{*} & =-\Pi(1) y_{t-1}^{*}+u_{t} \\
& =-\Lambda \Gamma^{\prime} y_{t-1}^{*}+u_{t}
\end{aligned}
$$

where $\Lambda, \Gamma \in \mathbb{R}^{N \times r}$. Since $\left\{\boldsymbol{y}_{t}^{*}\right\}$ is $\mathrm{CI}(1,1)$, the roots of $\operatorname{det}(\boldsymbol{\Pi}(z))=0$ must lie on or outside the unit circle. This requirement gives an implicit restriction on the VECM parameters $(\boldsymbol{\Phi}(),. \boldsymbol{\Lambda}, \boldsymbol{\Gamma})$.

We can write for all $t$,

$$
\begin{aligned}
\Phi(\mathrm{L})\left(\Delta \boldsymbol{y}_{t}-\boldsymbol{\mu}\right) & =-\Lambda \Gamma^{\prime}\left[\boldsymbol{y}_{t-1}-\boldsymbol{\alpha}-\boldsymbol{\mu}(t-1)\right]+\boldsymbol{u}_{t} \\
& =-\Lambda\left[\Gamma^{\prime} \boldsymbol{y}_{t-1}-\boldsymbol{\beta}-\boldsymbol{\delta}(t-1)\right]+\boldsymbol{u}_{t}
\end{aligned}
$$

where $\boldsymbol{\beta}:=\boldsymbol{\Gamma}^{\prime} \boldsymbol{\alpha}$ and $\boldsymbol{\delta}:=\boldsymbol{\Gamma}^{\prime} \boldsymbol{\mu}$. Though slightly different, the last expression is essentially a steady state VECM suggested by Villani (2009, p. 633). We have for all $t$,

$$
\begin{aligned}
\mathrm{E}\left(\Delta \boldsymbol{y}_{t}\right) & =\boldsymbol{\mu} \\
\mathrm{E}\left(\Gamma^{\prime} \boldsymbol{y}_{t}\right) & =\boldsymbol{\beta}+\boldsymbol{\delta} t
\end{aligned}
$$

which help us to specify an informative prior on $(\mu, \boldsymbol{\beta}, \boldsymbol{\delta})$. Thus a steady state VECM is useful for Bayesian analysis.

\subsection{State space representation}

Assume that $p \geq 1$. We have for all $t$,

$$
\begin{aligned}
\Gamma^{\prime} y_{t}^{*} & =\Gamma^{\prime}\left(y_{t-1}^{*}+\Phi_{1} \Delta y_{t-1}^{*}+\cdots+\Phi_{p} \Delta y_{t-p}^{*}-\Lambda \Gamma^{\prime} y_{t-1}^{*}+u_{t}\right) \\
& =\Gamma^{\prime} \Phi_{1} \Delta y_{t-1}^{*}+\cdots+\Gamma^{\prime} \Phi_{p} \Delta y_{t-p}^{*}+\left(I_{r}-\Gamma^{\prime} \Lambda\right) \Gamma^{\prime} y_{t-1}^{*}+\Gamma^{\prime} u_{t}
\end{aligned}
$$

or

$$
\begin{aligned}
\Gamma^{\prime} \boldsymbol{y}_{t}-\boldsymbol{\beta}-\delta t= & \Gamma^{\prime} \Phi_{1}\left(\Delta \boldsymbol{y}_{t-1}-\boldsymbol{\mu}\right)+\cdots+\Gamma^{\prime} \Phi_{p}\left(\Delta \boldsymbol{y}_{t-p}-\boldsymbol{\mu}\right) \\
& +\left(\boldsymbol{I}_{r}-\Gamma^{\prime} \Lambda\right)\left[\Gamma^{\prime} \boldsymbol{y}_{t-1}-\boldsymbol{\beta}-\delta(t-1)\right]+\Gamma^{\prime} \boldsymbol{u}_{t}
\end{aligned}
$$

Let $\boldsymbol{s}_{t}$ be a state vector such that for all $t$,

$$
\boldsymbol{s}_{t}:=\left(\begin{array}{c}
\Delta \boldsymbol{y}_{t}-\boldsymbol{\mu} \\
\vdots \\
\Delta \boldsymbol{y}_{t-p+1}-\boldsymbol{\mu} \\
\Gamma^{\prime} \boldsymbol{y}_{t}-\boldsymbol{\beta}-\delta t
\end{array}\right)
$$

which is $\mathrm{I}(0)$ and observable given the model parameters. A state space representation of the steady state VECM is for all $t$,

$$
\begin{aligned}
\boldsymbol{s}_{t} & =\boldsymbol{A} \boldsymbol{s}_{t-1}+\boldsymbol{B} \boldsymbol{z}_{t} \\
\Delta \boldsymbol{y}_{t} & =\boldsymbol{\mu}+\boldsymbol{C} \boldsymbol{s}_{t} \\
\left\{\boldsymbol{z}_{t}\right\} & \sim \mathrm{WN}\left(\boldsymbol{I}_{N}\right)
\end{aligned}
$$

where

$$
\boldsymbol{A}:=\left[\begin{array}{cccc}
\boldsymbol{\Phi}_{1} & \ldots & \boldsymbol{\Phi}_{p} & -\Lambda \\
& \boldsymbol{I}_{(p-1) N} & \mathbf{0}_{(p-1) N \times N} & \mathbf{0}_{(p-1) N \times r} \\
\Gamma^{\prime} \boldsymbol{\Phi}_{1} & \cdots & \Gamma^{\prime} \boldsymbol{\Phi}_{p} & \boldsymbol{I}_{r}-\Gamma^{\prime} \Lambda
\end{array}\right]
$$




$$
\begin{aligned}
& \boldsymbol{B}:=\left[\begin{array}{c}
\Sigma^{1 / 2} \\
\mathbf{0}_{(p-1) N \times N} \\
\Gamma^{\prime} \Sigma^{1 / 2}
\end{array}\right] \\
& \boldsymbol{C}:=\left[\begin{array}{lll}
\boldsymbol{I}_{N} & \mathbf{0}_{N \times(p-1) N} & \mathbf{0}_{N \times r}
\end{array}\right]
\end{aligned}
$$

with $\mathbf{O}_{m \times n}$ denoting an $m \times n$ null matrix. Note that $\left\{\boldsymbol{s}_{t}\right\}$ is $\mathrm{I}(0)$ if and only if the eigenvalues of $\boldsymbol{A}$ lie inside the unit circle.

We have for all $t$, for $h \geq 0$,

$$
\mathrm{E}_{t}\left(\Delta \boldsymbol{y}_{t+h}\right)=\boldsymbol{\mu}+\boldsymbol{C} \boldsymbol{A}^{h} \boldsymbol{s}_{t}
$$

or

$$
\begin{aligned}
\mathrm{E}_{t}\left(\Delta \boldsymbol{x}_{t+h, 1}\right) & =\boldsymbol{\mu}_{1}+\boldsymbol{C}_{1} \boldsymbol{A}^{h} \boldsymbol{s}_{t} \\
\mathrm{E}_{t}\left(\Delta^{2} \boldsymbol{x}_{t+h, 2}\right) & =\boldsymbol{\mu}_{2}+\boldsymbol{C}_{2} \boldsymbol{A}^{h} \boldsymbol{s}_{t}
\end{aligned}
$$

where

$$
\begin{aligned}
\boldsymbol{C}_{1}:=\left[\begin{array}{llll}
\boldsymbol{I}_{N_{1}} & \mathbf{0}_{N_{1} \times N_{2}} & \mathbf{0}_{N_{1} \times(p-1) N} & \mathbf{0}_{N_{1} \times r}
\end{array}\right] \\
\boldsymbol{C}_{2}:=\left[\begin{array}{llll}
\mathbf{0}_{N_{2} \times N_{1}} & \boldsymbol{I}_{N_{2}} & \mathbf{0}_{N_{2} \times(p-1) N} & \mathbf{0}_{N_{2} \times r}
\end{array}\right]
\end{aligned}
$$

\subsection{Multivariate $\mathrm{B}-\mathrm{N}$ decomposition}

Introducing cointegration changes the state space model, but the formulae for the multivariate B-N decomposition of I(1) and I(2) series given by Murasawa (2015, Theorem 1) remain almost unchanged. Let $\boldsymbol{x}_{t}^{*}$ and $\boldsymbol{c}_{t}$ be the B-N permanent and transitory components in $\boldsymbol{x}_{t}$, respectively.

Theorem 1. Suppose that the eigenvalues of $\boldsymbol{A}$ lie inside the unit circle. Then for all $t$,

$$
\begin{aligned}
& \boldsymbol{x}_{t, 1}^{*}=\lim _{T \rightarrow \infty}\left(\mathrm{E}_{t}\left(\boldsymbol{x}_{t+T, 1}\right)-T \boldsymbol{\mu}_{1}\right) \\
& \boldsymbol{x}_{t, 2}^{*}=\lim _{T \rightarrow \infty}\left\{\mathrm{E}_{t}\left(\boldsymbol{x}_{t+T, 2}\right)-T^{2} \frac{\boldsymbol{\mu}_{2}}{2}-T\left[\frac{\boldsymbol{\mu}_{2}}{2}+\Delta \boldsymbol{x}_{t, 2}+\boldsymbol{C}_{2}\left(\boldsymbol{I}_{p N+r}-\boldsymbol{A}\right)^{-1} \boldsymbol{A} \boldsymbol{s}_{t}\right]\right\} \\
& \boldsymbol{c}_{t, 1}=-\boldsymbol{C}_{1}\left(\boldsymbol{I}_{p N+r}-\boldsymbol{A}\right)^{-1} \boldsymbol{A} \boldsymbol{s}_{t} \\
& \boldsymbol{c}_{t, 2}=\boldsymbol{C}_{2}\left(\boldsymbol{I}_{p N+r}-\boldsymbol{A}\right)^{-2} \boldsymbol{A}^{2} \boldsymbol{s}_{t}
\end{aligned}
$$

Proof. See Murasawa (2015, pp. 158-159).

Let

$$
\boldsymbol{W}:=\left[\begin{array}{l}
-\boldsymbol{C}_{1}\left(\boldsymbol{I}_{p N+r}-\boldsymbol{A}\right)^{-1} \boldsymbol{A} \\
\boldsymbol{C}_{2}\left(\boldsymbol{I}_{p N+r}-\boldsymbol{A}\right)^{-2} \boldsymbol{A}^{2}
\end{array}\right]
$$

Then for all $t$,

$$
\boldsymbol{c}_{t}=\boldsymbol{W} \boldsymbol{s}_{t}
$$

where $\boldsymbol{W}$ depends only on the VECM coefficients and $\left\{\boldsymbol{s}_{t}\right\}$ is observable given the model parameters. This observation is useful for Bayesian analysis of $\left\{\boldsymbol{c}_{t}\right\}$. 


\section{Bayesian analysis}

\subsection{Conditional likelihood function}

Assume Gaussian innovations for Bayesian analysis, and write the VECM as for all $t$,

$$
\begin{gathered}
\Delta \boldsymbol{y}_{t}-\boldsymbol{\mu}=\Phi_{1}\left(\Delta \boldsymbol{y}_{t-1}-\boldsymbol{\mu}\right)+\cdots+\Phi_{p}\left(\Delta \boldsymbol{y}_{t-p}-\boldsymbol{\mu}\right)-\Lambda\left[\Gamma^{\prime} \boldsymbol{y}_{t-1}-\boldsymbol{\beta}-\Gamma^{\prime} \boldsymbol{\mu}(t-1)\right]+\boldsymbol{u}_{t} \\
\left\{\boldsymbol{u}_{t}\right\} \sim \mathrm{IN}_{N}\left(\mathbf{0}_{N}, \boldsymbol{P}^{-1}\right)
\end{gathered}
$$

where $\operatorname{IN}_{N}\left(\mathbf{0}_{N}, \boldsymbol{P}^{-1}\right)$ means 'independent $N$-variate normal distributions with mean vector $\mathbf{0}_{N}$ (null vector) and variance-covariance matrix $\boldsymbol{P}^{-1}$. Let $\boldsymbol{\psi}:=\left(\boldsymbol{\beta}^{\prime}, \boldsymbol{\mu}^{\prime}\right)^{\prime}, \boldsymbol{\Phi}:=\left[\boldsymbol{\Phi}_{1}, \ldots, \boldsymbol{\Phi}_{p}\right]$, and $\boldsymbol{Y}:=\left[\boldsymbol{y}_{0}, \ldots, \boldsymbol{y}_{T}\right] \cdot{ }^{11}$ By the prediction error decomposition, the joint pdf of $\boldsymbol{Y}$ is ${ }^{12}$

$$
\begin{aligned}
p(\boldsymbol{Y} \mid \boldsymbol{\psi}, \boldsymbol{\Phi}, \boldsymbol{P}, \Lambda, \Gamma) & =p\left(\Delta \boldsymbol{y}_{T}, \ldots, \Delta \boldsymbol{y}_{p+1}, \boldsymbol{s}_{p} \mid \boldsymbol{\psi}, \boldsymbol{\Phi}, \boldsymbol{P}, \Lambda, \Gamma\right) \\
& =\prod_{t=p+1}^{T} p\left(\Delta \boldsymbol{y}_{t} \mid \boldsymbol{s}_{t-1}, \boldsymbol{\psi}, \boldsymbol{\Phi}, \boldsymbol{P}, \Lambda, \Gamma\right) p\left(\boldsymbol{s}_{p} \mid \boldsymbol{\psi}, \boldsymbol{\Phi}, \boldsymbol{P}, \Lambda, \Gamma\right)
\end{aligned}
$$

Our Bayesian analysis relies on $\prod_{t=p+1}^{T} p\left(\Delta \boldsymbol{y}_{t} \mid \boldsymbol{s}_{t-1}, \boldsymbol{\psi}, \boldsymbol{\Phi}, \boldsymbol{P}, \Lambda, \Gamma\right)$, which is equivalent to the conditional likelihood function of $(\boldsymbol{\psi}, \boldsymbol{\Phi}, \boldsymbol{P}, \boldsymbol{\Lambda}, \boldsymbol{\Gamma})$ given $\boldsymbol{s}_{p}$.

\subsection{Identification}

Identification of $(\boldsymbol{\Lambda}, \boldsymbol{\Gamma})$ from $\boldsymbol{\Pi}(1)$ requires some restrictions, though such identification is unnecessary for the multivariate $\mathrm{B}-\mathrm{N}$ decomposition. Let

$$
\Lambda_{*}:=\Lambda\left(\Gamma^{\prime} \Gamma\right)^{1 / 2}, \quad \Gamma_{*}:=\Gamma\left(\Gamma^{\prime} \Gamma\right)^{-1 / 2}
$$

Then $\boldsymbol{\Lambda}_{*} \boldsymbol{\Gamma}_{*}^{\prime}=\boldsymbol{\Lambda} \boldsymbol{\Gamma}^{\prime}$ and $\boldsymbol{\Gamma}_{*}^{\prime} \boldsymbol{\Gamma}_{*}=\boldsymbol{I}_{r}$. These restrictions are common, but do not identify the signs of $\boldsymbol{\Lambda}_{*}$ and $\Gamma_{*}$.

Alternatively, we can apply linear normalization. Write $\boldsymbol{\Gamma}:=\left[\boldsymbol{\Gamma}_{1}^{\prime}, \boldsymbol{\Gamma}_{2}^{\prime}\right]^{\prime}$, where $\boldsymbol{\Gamma}_{1}$ is $r \times r$ and $\boldsymbol{\Gamma}_{2}$ is $(N-r) \times r$. Let

$$
\bar{\Lambda}:=\Lambda \Gamma_{1}, \quad \bar{\Gamma}:=\Gamma \Gamma_{1}^{-1}
$$

Then we can identify $(\bar{\Lambda}, \bar{\Gamma})$. Let $\overline{\boldsymbol{\beta}}:=\bar{\Gamma}^{\prime} \boldsymbol{\alpha}=\left(\Gamma_{1}^{-1}\right)^{\prime} \boldsymbol{\beta}$ and $\overline{\boldsymbol{\psi}}:=\left(\overline{\boldsymbol{\beta}}^{\prime}, \boldsymbol{\mu}^{\prime}\right)^{\prime}$ correspondingly. Note that $\boldsymbol{\alpha}$ is not identifiable from the VECM.

\subsection{Prior}

\subsubsection{Steady state parameters}

Assume that

$$
p(\boldsymbol{\alpha}, \boldsymbol{\mu}, \boldsymbol{\Phi}, \boldsymbol{P}, \Lambda, \Gamma)=p(\boldsymbol{\alpha}, \boldsymbol{\mu}) p(\Phi, \boldsymbol{P}, \Lambda, \Gamma)
$$

11 With a slight abuse of notation, $\boldsymbol{\Phi}$ denotes the VAR coefficient matrices in $\boldsymbol{\Phi}($.).

12 We use the same $p$ (.) to denote different distributions, which is common in the Bayesian literature; see, e.g., Gelman et al. (2014, p. 6). 
Assume a normal prior on $(\boldsymbol{\alpha}, \boldsymbol{\mu})$ such that

$$
\left(\begin{array}{c}
\boldsymbol{\alpha} \\
\boldsymbol{\mu}
\end{array}\right) \sim \mathrm{N}_{2 N}\left(\left(\begin{array}{c}
\boldsymbol{\alpha}_{0} \\
\boldsymbol{\mu}_{0}
\end{array}\right),\left[\begin{array}{cc}
\boldsymbol{Q}_{0, \boldsymbol{\alpha}}^{-1} & \mathbf{o}_{N \times N} \\
\mathbf{0}_{N \times N} & \boldsymbol{Q}_{0, \boldsymbol{\mu}}^{-1}
\end{array}\right]\right)
$$

where $\boldsymbol{Q}_{0, \boldsymbol{\alpha}}$ and $\boldsymbol{Q}_{0, \boldsymbol{\mu}}$ are the prior precision matrices of $\boldsymbol{\alpha}$ and $\boldsymbol{\mu}$, respectively. Since $\boldsymbol{\beta}:=\boldsymbol{\Gamma}^{\prime} \boldsymbol{\alpha}$, this prior implies a prior on $\psi$ such that

$$
\boldsymbol{\psi} \mid \Gamma \sim \mathrm{N}_{r+N}\left(\boldsymbol{\psi}_{0}, \boldsymbol{Q}_{0}^{-1}\right)
$$

where

$$
\boldsymbol{\psi}_{0}:=\left(\begin{array}{c}
\Gamma^{\prime} \boldsymbol{\alpha}_{0} \\
\boldsymbol{\mu}_{0}
\end{array}\right), \quad \boldsymbol{Q}_{0}:=\left[\begin{array}{cc}
\left(\Gamma^{\prime} \mathbf{Q}_{0, \boldsymbol{\alpha}}^{-1} \Gamma\right)^{-1} & \mathbf{0}_{r \times r} \\
\mathbf{0}_{N \times N} & \boldsymbol{Q}_{0, \mu}
\end{array}\right]
$$

which depends on $\boldsymbol{\Gamma}$ in general.

\subsubsection{VAR parameters}

Let $S$ be the set of $(\boldsymbol{\Phi}, \boldsymbol{\Lambda}, \boldsymbol{\Gamma})$ such that the eigenvalues of $\boldsymbol{A}$ lie inside the unit circle, so that $\left\{\boldsymbol{y}_{t}^{*}\right\}$ is $\mathrm{CI}(1,1)$. Write

$$
p(\Phi, \boldsymbol{P}, \Lambda, \Gamma) \propto p^{*}(\Phi, \boldsymbol{P}, \Lambda, \Gamma)[(\Phi, \Lambda, \Gamma) \in S]
$$

where $p^{*}($.$) is the pdf with no truncation of (\boldsymbol{\Phi}, \boldsymbol{\Lambda}, \boldsymbol{\Gamma})$ and [.] is the indicator function that truncates the support of $p^{*}($.) to $S$. Assume that

$$
p^{*}(\boldsymbol{\Phi}, \boldsymbol{P}, \Lambda, \Gamma)=p^{*}(\boldsymbol{\Phi}, \boldsymbol{P}) p^{*}(\Lambda, \Gamma)
$$

Assume a hierarchical normal-Wishart prior on $(\boldsymbol{\Phi}, \boldsymbol{P})$ such that

$$
\begin{aligned}
\Phi \mid \boldsymbol{P}, v & \sim \mathrm{N}_{N \times \mathrm{pN}}\left(\boldsymbol{M}_{0} ; \boldsymbol{P}^{-1},\left(v \boldsymbol{D}_{0}\right)^{-1}\right) \\
\boldsymbol{P} & \sim \mathrm{W}_{N}\left(k_{0} ; \boldsymbol{S}_{0}^{-1}\right) \\
v & \sim \operatorname{Gam}\left(\frac{A_{0}}{2}, \frac{B_{0}}{2}\right)
\end{aligned}
$$

where $v$ is a hyperparameter that controls the tightness of the prior on the VAR coefficients, $\mathrm{W}_{N}\left(k_{0} ; \boldsymbol{S}_{0}^{-1}\right)$ means 'an $(N \times N)$-variate Wishart distribution with $k_{0}$ degrees of freedom and scale matrix $\boldsymbol{S}_{0}^{-1}$ ', and $\operatorname{Gam}\left(A_{0} / 2, B_{0} / 2\right)$ means 'a gamma distribution with shape $A_{0} / 2$ and rate $B_{0} / 2$ '. Since it is often difficult to choose $v$ a priori, we assume a gamma prior on $v$.

\subsubsection{Cointegrating space}

Assume that

$$
p^{*}(\Lambda, \Gamma)=p^{*}(\Lambda) p^{*}(\Gamma)
$$

Assume a normal prior on $\boldsymbol{\Lambda}$ such that

$$
\Lambda \sim \mathrm{N}_{N \times r}\left(\mathbf{0}_{N \times r} ;\left(\eta_{0} \boldsymbol{G}_{0}\right)^{-1}, \boldsymbol{I}_{r}\right)
$$

where $\eta_{0} \boldsymbol{G}_{0}$ is the prior precision matrix of each column of $\boldsymbol{\Lambda}$.

Let $V_{r}\left(\mathbb{R}^{N}\right)$ be the $r$-dimensional Steifel manifold in $\mathbb{R}^{N}$, i.e.,

$$
V_{r}\left(\mathbb{R}^{N}\right):=\left\{\boldsymbol{H} \in \mathbb{R}^{N \times r}: \boldsymbol{H}^{\prime} \boldsymbol{H}=\boldsymbol{I}_{r}\right\}
$$

Let $\boldsymbol{H}_{0} \in V_{r}\left(\mathbb{R}^{N}\right)$. Let $\boldsymbol{H}($.) be such that $\forall \tau \geq 0$,

$$
\boldsymbol{H}(\tau):=\boldsymbol{H}_{0} \boldsymbol{H}_{0}^{\prime}+\tau \boldsymbol{H}_{0 \perp} \boldsymbol{H}_{0 \perp}^{\prime}
$$


where $\boldsymbol{H}_{0 \perp} \in V_{N-r}\left(\mathbb{R}^{N}\right)$ lies in the orthogonal complement of the column space of $\boldsymbol{H}_{0}$, so that $\boldsymbol{H}(0)=\boldsymbol{H}_{0} \boldsymbol{H}_{0}^{\prime}$ is of rank $r$ and $\boldsymbol{H}(1)=\boldsymbol{I}_{N}$. Assume a normal prior on $\boldsymbol{\Gamma}$ such that

$$
\Gamma \sim \mathrm{N}_{N \times r}\left(\mathbf{o}_{N \times r} ; \boldsymbol{H}\left(\tau_{0}\right)^{-1}, \boldsymbol{I}_{r}\right)
$$

where $\tau_{0} \neq 0$. This prior on $\boldsymbol{\Gamma}$ implies a prior on $\boldsymbol{\Gamma}_{*}$ such that

$$
\Gamma_{*} \sim \operatorname{MACG}_{N \times r}\left(\boldsymbol{H}\left(\tau_{0}\right)^{-1}\right)
$$

where $\tau_{0}:=1$ implies the flat prior on $V_{r}\left(\mathbb{R}^{N}\right)$; see Chikuse (2003, sec. 2.4.2). Note that $p^{*}\left(\boldsymbol{\Lambda}_{*} \mid \boldsymbol{\Gamma}\right)$ is normal, but $p^{*}\left(\boldsymbol{\Lambda}_{*} \mid \boldsymbol{\Gamma}_{*}\right)$ is not; see Koop, León-González, and Strachan (2010, p. 232), who use these priors on $(\boldsymbol{\Lambda}, \boldsymbol{\Gamma})$ for their parameter-augmented Gibbs sampler.

\subsection{Posterior simulation}

We simulate $p(\boldsymbol{\psi}, \boldsymbol{\Phi}, \boldsymbol{P}, \boldsymbol{\Lambda}, \boldsymbol{\Gamma}, \nu \mid \boldsymbol{Y})$ by a Gibbs sampler consisting of five blocks:

1. Draw $\boldsymbol{\psi}$ from $p(\boldsymbol{\psi} \mid \boldsymbol{\Phi}, \boldsymbol{P}, \boldsymbol{\Lambda}, \boldsymbol{\Gamma}, \nu, \boldsymbol{Y})=p(\boldsymbol{\psi} \mid \boldsymbol{\Phi}, \boldsymbol{P}, \boldsymbol{\Lambda}, \boldsymbol{\Gamma}, \boldsymbol{Y})$.

2. Draw $(\boldsymbol{\Phi}, \boldsymbol{P})$ from $p^{*}(\boldsymbol{\Phi}, \boldsymbol{P} \mid \boldsymbol{\psi}, \boldsymbol{\Lambda}, \boldsymbol{\Gamma}, v, Y)$.

3. Draw $\boldsymbol{\Lambda}$ from $p^{*}(\boldsymbol{\Lambda} \mid \boldsymbol{\psi}, \boldsymbol{\Phi}, \boldsymbol{P}, \boldsymbol{\Gamma}, v, \boldsymbol{Y})=p^{*}(\boldsymbol{\Lambda} \mid \psi, \boldsymbol{\Phi}, \boldsymbol{P}, \boldsymbol{\Gamma}, \boldsymbol{Y})$.

4. Draw $\boldsymbol{\Gamma}$ from $p^{*}(\boldsymbol{\Gamma} \mid \boldsymbol{\psi}, \boldsymbol{\Phi}, \boldsymbol{P}, \boldsymbol{\Lambda}, v, \boldsymbol{Y})=p^{*}(\boldsymbol{\Gamma} \mid \boldsymbol{\psi}, \boldsymbol{\Phi}, \boldsymbol{P}, \boldsymbol{\Lambda}, \boldsymbol{Y})$. Accept the draw if $(\boldsymbol{\Phi}, \boldsymbol{\Lambda}, \boldsymbol{\Gamma}) \in S$; otherwise go back to step 2 and draw another $(\boldsymbol{\Phi}, \boldsymbol{P}, \boldsymbol{\Lambda}, \boldsymbol{\Gamma})$.

5. Draw $v$ from $p(v \mid \boldsymbol{\psi}, \boldsymbol{\Phi}, \boldsymbol{P}, \boldsymbol{\Lambda}, \boldsymbol{\Gamma}, \boldsymbol{Y})=p(\nu \mid \boldsymbol{\Phi}, \boldsymbol{P})$.

The first block builds on Villani (2009); the second block is standard; the third and fourth blocks follow the parameter-augmented Gibbs sampler proposed by Koop, León-González, and Strachan (2010); the fifth block is standard. See the Appendix for the details of each block.

\subsection{Bayes factor}

We use the Bayes factor for Bayesian model selection. When choosing between nested models with certain priors, the Savage-Dickey (S-D) density ratio gives the Bayes factor without estimating the marginal likelihoods; see Wagenmakers et al. (2010) for a tutorial on the S-D method.

We choose the cointegrating rank $r$. Consider comparing the following two models (hypotheses):

$$
H_{0}: \operatorname{rk}(\Pi(1))=0 \quad \text { vs } \quad H_{r}: \operatorname{rk}(\Pi(1))=r
$$

Koop, León-González, and Strachan (2008, pp. 451-452) note that the problem is the same as comparing the following two nested models:

$$
H_{0}: \Lambda=\mathbf{0}_{N \times r} \quad \text { vs } \quad H_{r}: \Lambda \neq \mathbf{0}_{N \times r}
$$

The restriction $(\boldsymbol{\Phi}, \boldsymbol{\Lambda}, \boldsymbol{\Gamma}) \in S$ is necessary only for the B-N decomposition, and unnecessary for forecasting in general; hence we ignore this restriction for the moment, so that the priors on $\boldsymbol{\Lambda}$ and $\boldsymbol{\Gamma}$ become independent. ${ }^{13}$ Then the S-D density ratio for $H_{0}$ versus $H_{r}$ is

$$
B_{0, r}=\frac{p\left(\Lambda=\mathbf{0}_{N \times r} \mid \boldsymbol{Y} ; H_{r}\right)}{p\left(\Lambda=\mathbf{0}_{N \times r} \mid H_{r}\right)}
$$

The prior gives the denominator directly. For the numerator, we have

$$
p\left(\Lambda \mid \boldsymbol{Y} ; H_{r}\right)=\mathrm{E}\left(p\left(\Lambda \mid \boldsymbol{\Psi}, \boldsymbol{\Phi}, \boldsymbol{P}, \Gamma, \boldsymbol{Y} ; H_{r}\right) \mid \boldsymbol{Y} ; H_{r}\right)
$$

13 If the priors on $\boldsymbol{\Lambda}$ and $\boldsymbol{\Gamma}$ are dependent, then we can use the generalized S-D density ratio proposed by Verdinelli and Wasserman (1995). 
Let $\left\{\boldsymbol{\psi}_{l}, \Phi_{l}, \boldsymbol{P}_{l}, \Gamma_{l}\right\}_{l=1}^{L}$ be posterior draws. Let

$$
\hat{p}\left(\Lambda=\mathbf{0}_{N \times r} \mid \boldsymbol{Y} ; H_{r}\right):=\frac{1}{L} \sum_{l=1}^{L} p\left(\Lambda=\mathbf{0}_{N \times r} \mid \boldsymbol{\Psi}_{l}, \boldsymbol{\Phi}_{l}, \boldsymbol{P}_{l}, \Gamma_{l}, \boldsymbol{Y} ; H_{r}\right)
$$

See Appendix A.4 for the conditional posterior $p(\boldsymbol{\Lambda} \mid \boldsymbol{\psi}, \boldsymbol{\Phi}, \boldsymbol{P}, \boldsymbol{\Gamma}, \boldsymbol{Y})$. An estimator of the S-D density ratio for $H_{0}$ versus $H_{r}$ is

$$
\hat{B}_{0, r}=\frac{\hat{p}\left(\Lambda=\mathbf{0}_{N \times r} \mid \boldsymbol{Y} ; H_{r}\right)}{p\left(\Lambda=\mathbf{0}_{N \times r} \mid H_{r}\right)}
$$

\section{Application}

\subsection{Data}

We consider joint estimation of the natural rates (or their permanent components) and gaps of the following four macroeconomic variables in the US:

1. Output Let $Y_{t}$ be output. Assume that $\left\{\ln Y_{t}\right\}$ is $\mathrm{I}(2)$, so that $\left\{\Delta \ln Y_{t}\right\}$ is I(1).

2. Inflation rate Let $P_{t}$ be the price level and $\pi_{t}:=\ln \left(P_{t} / P_{t-1}\right)$ be the inflation rate. Assume that $\left\{\pi_{t}\right\}$ is $\mathrm{I}(1)$.

3. Interest rate Let $I_{t}$ be the 3-month nominal interest rate (annual rate in per cent), $i_{t}:=\ln \left(1+I_{t} / 400\right)$, $r_{t}:=i_{t}-E_{t}\left(\pi_{t+1}\right)$ be the ex ante real interest rate, and $\hat{r}_{t}:=i_{t}-\pi_{t+1}$ be the ex post real interest rate. Assume that $\left\{r_{t}\right\}$ is I(1). ${ }^{14}$

4. Unemployment rate Let $L_{t}$ be the labor force, $E_{t}$ be employment, and $U_{t}:=-\ln \left(E_{t} / L_{t}\right)$ be the unemployment rate. Assume that $\left\{U_{t}\right\}$ is $\mathrm{I}(1)$.

Table 1 describes the data, which are available from FRED (Federal Reserve Economic Data). When monthly series are available, i.e., except for real GDP, we take the 3-month arithmetic means of monthly series each quarter to obtain quarterly series, from which we construct the quarterly inflation, interest, and unemployment rates as defined above.

Let for all $t$,

$$
\boldsymbol{x}_{t}:=\left(\begin{array}{c}
\pi_{t} \\
\hat{r}_{t} \\
U_{t} \\
\ln Y_{t}
\end{array}\right), \quad \boldsymbol{y}_{t}:=\left(\begin{array}{c}
\pi_{t} \\
\hat{r}_{t} \\
U_{t} \\
\Delta \ln Y_{t}
\end{array}\right)
$$

The sample period of $\left\{\boldsymbol{y}_{t}\right\}$ is 1948Q1-2018Q4 (284 observations). Table 2 shows summary statistics of $\left\{\boldsymbol{y}_{t}\right\}$ and $\left\{\Delta \boldsymbol{y}_{t}\right\}$ multiplied by 100 . Note that $\left\{\pi_{t}\right\},\left\{\hat{r}_{t}\right\}$, and $\left\{\Delta \ln Y_{t}\right\}$ are quarterly rates (not annualized).

\subsection{Preliminary analyses}

As preliminary analyses, we check if $\left\{\boldsymbol{y}_{t}\right\}$ is indeed I(1), though our method is valid even if some series in $\left\{\boldsymbol{y}_{t}\right\}$ are I(0). For each I(0) series, we treat it as an I(1) series cointegrated with itself, and increase the cointegrating rank by 1 as 'pseudo' cointegration; see Fisher, Huh, and Pagan (2016, sec. 2.2).

Table 3 shows the results of the ADF and ADF-GLS tests for unit root, with or without constant and/or trend terms in the ADF regression. ${ }^{15}$ The results depend on the number of lags included in the ADF regression, since the ADF test suffers from size distortion with short lags and low power with long lags. The ADF-GLS test mitigates the problem except when there is no constant nor trend term in the ADF regression, in which case

14 We can estimate the interest rate gap even if we observe $\left\{\hat{r}_{t}\right\}$ instead of $\left\{r_{t}\right\}$. See Murasawa (2014, pp. 499-500). 15 We use gretl 2021a for our preliminary analyses. 
Table 1: Data.

\begin{tabular}{ll}
\hline Variable & Description \\
\hline$Y_{t}$ & Real GDP (billions of chained 2012 dollars, SA, AR) \\
$P_{t}$ & CPI for all urban consumers: all items (1982-84 =100, SA) \\
$I_{t}$ & 3-month treasury bill: secondary market rate $(\%, A R)$ \\
$L_{t}$ & Civilian labor force (thousands of persons, SA) \\
$E_{t}$ & Civilian employment level (thousands of persons, SA) \\
\hline
\end{tabular}

SA means 'seasonally-adjusted'; AR means 'annual rate'.

Table 2: Summary statistics.

\begin{tabular}{lrrrrrr}
\hline Variable & Min. & 1st qu. & Median & Mean & 3rd qu. & Max. \\
\hline $100 \pi_{t}$ & -2.32 & 0.39 & 0.75 & 0.84 & 1.10 & 3.98 \\
$100 \hat{r}_{t}$ & -3.65 & -0.24 & 0.23 & 0.19 & 0.55 & 2.69 \\
$100 U_{t}$ & 2.64 & 4.75 & 5.72 & 5.95 & 7.07 & 11.28 \\
$100 \Delta \ln Y_{t}$ & -2.63 & 0.31 & 0.76 & 0.78 & 1.25 & 3.85 \\
\hline $100 \Delta \pi_{t}$ & -3.85 & -0.26 & 0.00 & -0.01 & 0.28 & 1.98 \\
$100 \Delta \hat{r}_{t}$ & -1.95 & -0.27 & 0.02 & 0.01 & 0.25 & 3.81 \\
$100 \Delta U_{t}$ & -1.03 & -0.20 & -0.07 & 0.00 & 0.12 & 1.79 \\
$100 \Delta^{2} \ln Y_{t}$ & -2.79 & -0.71 & -0.02 & 0.00 & 0.62 & 4.70 \\
\hline
\end{tabular}

the ADF test is asymptotically point optimal. The level 0.05 ADF-GLS test rejects $H_{0}:\left\{y_{t, i}\right\} \sim \mathrm{I}(1)$ in favor of $H_{1}:\left\{y_{t, i}\right\} \sim \mathrm{I}(0)$ for $\left\{\Delta \ln Y_{t}\right\}$ (and possibly for $\left\{\pi_{t}\right\}$, whose results are mixed). Hence these unit root tests do not support our assumption that $\left\{\boldsymbol{y}_{t}\right\}$ is I(1).

Table 4 shows the results of the KPSS stationarity tests, with or without a trend term. The results depend on the lag truncation parameter for the Newey-West estimator of the long-run error variance. With a trend term, the level 0.05 KPSS test rejects $H_{0}:\left\{y_{t, i}\right\} \sim \mathrm{I}(0)$ in favor of $H_{1}:\left\{y_{t, i}\right\} \sim \mathrm{I}(1)$ except for $\left\{\Delta \ln Y_{t}\right\}$. With no trend term, the test rejects $H_{0}:\left\{y_{t, i}\right\} \sim \mathrm{I}(0)$ in favor of $H_{1}:\left\{y_{t, i}\right\} \sim \mathrm{I}(1)$ except for $\left\{\hat{r}_{t}\right\}$. Though the results for $\left\{\hat{r}_{t}\right\}$ and $\left\{\Delta \ln Y_{t}\right\}$ are mixed, these stationarity tests support our assumption that $\left\{\boldsymbol{y}_{t}\right\}$ is I(1).

Overall, these unit root and stationarity tests confirm that $\left\{\Delta y_{t}\right\}$ is I(0), but are inconclusive if each component of $\left\{\boldsymbol{y}_{t}\right\}$ is I(1). We can still proceed with our assumption that $\left\{\boldsymbol{y}_{t}\right\}$ is I(1), allowing for 'pseudo' cointegration.

As preliminary analyses, we also check if $\left\{\boldsymbol{y}_{t}\right\}$ is $\mathrm{CI}(1,1)$. Table 5 shows the results of the Engle-Granger cointegration tests, with or without a trend term in the cointegrating regression and for each choice of the left-hand side (LHS) variable. The results depend on the number of lags included in the ADF regression for the residual series, but the level 0.05 test rejects the null of no cointegration in favor of the alternative of cointegration only when we put $\Delta \ln Y_{t}$ on the LHS of the cointegrating regression.

Table 6 shows the results of Johansen's cointegration tests, with unrestricted constant and restricted trend terms in the VECM. The results depend on the number of lags included in the VECM, but overall, the tests suggest that the cointegrating rank is 2, possibly including 'pseudo' cointegration.

Since the results of these cointegration tests are mixed, we estimate VECMs with different cointegrating ranks, and use the Bayes factor to choose the cointegrating rank.

\subsection{Model specification}

For our data, $N:=4$. To select $p$, we fit VAR models to $\left\{\boldsymbol{y}_{t}\right\}$ up to VAR(8), i.e., $p=7$, and check model selection criteria. The common estimation period is 1950Q1-2018Q4. Table 7 summarizes the results of lag 
Table 3: Unit root tests.

\begin{tabular}{|c|c|c|c|c|c|c|c|}
\hline \multirow[t]{2}{*}{ Variable } & \multirow[t]{2}{*}{ Const. } & \multirow[t]{2}{*}{ Trend } & \multicolumn{3}{|c|}{ ADF } & \multicolumn{2}{|c|}{ ADF-GLS } \\
\hline & & & Lags & $\tau$ & $p$-value & Lags & $\tau$ \\
\hline$\pi_{t}$ & Yes & Yes & 4 & -3.73 & 0.02 & 4 & $-3.40^{* *}$ \\
\hline$\hat{r}_{t}$ & Yes & Yes & 7 & -3.89 & 0.01 & 5 & $-2.70^{*}$ \\
\hline$U_{t}$ & Yes & Yes & 13 & -2.87 & 0.17 & 12 & -2.19 \\
\hline$\Delta \ln Y_{t}$ & Yes & Yes & 11 & -5.78 & 0.00 & 1 & $-8.30^{* * *}$ \\
\hline$\pi_{t}$ & Yes & No & 4 & -3.69 & 0.00 & 12 & -0.75 \\
\hline$\hat{r}_{t}$ & Yes & No & 7 & -3.90 & 0.00 & 5 & -1.58 \\
\hline$U_{t}$ & Yes & No & 13 & -3.01 & 0.03 & 12 & -1.49 \\
\hline$\Delta \ln Y_{t}$ & Yes & No & 2 & -8.30 & 0.00 & 1 & $-6.36^{* * *}$ \\
\hline$\overline{\Delta \pi_{t}}$ & Yes & No & 3 & -11.88 & 0.00 & 0 & $-13.90^{* * *}$ \\
\hline$\Delta \hat{r}_{t}$ & Yes & No & 8 & -8.72 & 0.00 & 0 & $-21.61^{* * *}$ \\
\hline$\Delta U_{t}$ & Yes & No & 12 & -5.21 & 0.00 & 0 & $-7.47^{* * *}$ \\
\hline$\Delta^{2} \ln Y_{t}$ & Yes & No & 14 & -7.52 & 0.00 & 0 & $-25.16^{* * *}$ \\
\hline$\overline{\Delta \pi_{t}}$ & No & No & 3 & -11.90 & 0.00 & & \\
\hline$\Delta \hat{r}_{t}$ & No & No & 8 & -8.75 & 0.00 & & \\
\hline$\Delta U_{t}$ & No & No & 12 & -5.22 & 0.00 & & \\
\hline$\Delta^{2} \ln Y_{t}$ & No & No & 14 & -7.53 & 0.00 & & \\
\hline
\end{tabular}

For the ADF-GLS test, ${ }^{*},{ }^{* *}$, and ${ }^{* * *}$ denote significance at the $10 \%, 5 \%$, and $1 \%$ levels, respectively. For the number of lags included in the ADF regression, we use the default choice in gretl 2021a with maximum 15, where the lag order selection criteria are AIC for the ADF test, and a modified AIC using the Perron and Qu (2007) method for the ADF-GLS test. With no constant nor trend in the ADF regression, the ADF test is asymptotically point optimal; hence the ADF-GLS test is unnecessary.

Table 4: KPSS stationarity tests.

\begin{tabular}{lll}
\hline Variable & Trend & \multicolumn{1}{c}{ LM } \\
\hline$\pi_{t}$ & Yes & $0.53^{* * *}$ \\
$\hat{r}_{t}$ & Yes & $0.32^{* * *}$ \\
$U_{t}$ & Yes & $0.23^{* * *}$ \\
$\Delta \ln Y_{t}$ & Yes & 0.03 \\
\hline$\pi_{t}$ & No & $0.58^{* *}$ \\
$\hat{r}_{t}$ & No & 0.34 \\
$U_{t}$ & No & $0.63^{* *}$ \\
$\Delta \ln Y_{t}$ & No & $0.48^{* *}$ \\
\hline$\Delta \pi_{t}$ & No & 0.03 \\
$\Delta \hat{r}_{t}$ & No & 0.04 \\
$\Delta U_{t}$ & No & 0.07 \\
$\Delta^{2} \ln Y_{t}$ & No & 0.01 \\
\hline
\end{tabular}

** and ${ }^{* * *}$ denote significance at the 5 and $1 \%$ levels, respectively. The lag truncation parameter for the Newey-West estimator of the long-run error variance is 5 (the default value for our sample length in gretl 2021a).

order selection. ${ }^{16}$ The level 0.05 LR test fails to reject $H_{0}:\left\{\boldsymbol{y}_{t}\right\} \sim \operatorname{VAR}(7)$ against $H_{1}:\left\{\boldsymbol{y}_{t}\right\} \sim \operatorname{VAR}(8)$ and AIC

16 The standard lag order selection criteria are valid even when $\left\{\boldsymbol{y}_{t}\right\}$ is I(1); see Kilian and Lütkepohl (2017, pp. 99-100). 
selects VAR(7), but BIC and HQC select much smaller models. Since a high-order VAR model covers low-order VAR models as special cases, to be conservative, we choose a $\operatorname{VAR}(8)$ model for $\left\{\boldsymbol{y}_{t}\right\}$, i.e., $p=7$, and impose a shrinkage prior on the VAR coefficients in the VECM.

For the prior on $\boldsymbol{\alpha}$, we set $\boldsymbol{\alpha}_{0}:=\mathbf{0}_{N}$ and $\boldsymbol{Q}_{0, \boldsymbol{\alpha}}:=\boldsymbol{I}_{N}$. For the prior on $\boldsymbol{\mu}$, we set $\boldsymbol{\mu}_{0}:=\hat{\boldsymbol{\mu}}$, where $\hat{\boldsymbol{\mu}}$ is the sample mean of $\left\{\Delta \boldsymbol{y}_{t}\right\}$, and $\boldsymbol{Q}_{0, \mu}:=\boldsymbol{I}_{N}$.

Following Kadiyala and Karlsson (1997) and Bańbura, Giannone, and Reichlin (2010), we set

$$
\begin{aligned}
\boldsymbol{M}_{0} & :=\mathbf{0}_{N \times p N} \\
\boldsymbol{D}_{0} & :=\operatorname{diag}(1, \ldots, p)^{2} \otimes \operatorname{diag}\left(s_{1}, \ldots, s_{N}\right)^{2} \\
k_{0} & :=N+2 \\
\boldsymbol{S}_{0} & :=\left(k_{0}-N-1\right) \operatorname{diag}\left(s_{1}, \ldots, s_{N}\right)^{2}
\end{aligned}
$$

where for $i=1, \ldots, N, s_{i}^{2}$ is an estimate of $\operatorname{var}\left(u_{t, i}\right)$ based on the univariate $\operatorname{AR}(p+1)$ model with constant and trend terms for $\left\{y_{t, i}\right\}$.

For the prior on $\boldsymbol{\Lambda}$, we set $\eta_{0}:=1$ and $\boldsymbol{G}_{0}:=\boldsymbol{I}_{N}$. For the prior on $\boldsymbol{\Gamma}$, we set $\tau_{0}:=1$, which gives the flat prior on the cointegrating space.

For the prior on $v$, we set $A_{0}:=1$ and $B_{0}:=1$, i.e., $v \sim \chi^{2}(1)$; hence the tightness hyperparameter on the VAR coefficients tends to be small, implying potentially mild shrinkage toward $\boldsymbol{M}_{0}:=\mathbf{0}_{N \times p N}$.

Overall, our priors are weakly informative in the sense of Gelman et al. (2014, p. 55).

\subsection{Bayesian computation}

We run our Gibbs sampler on R 4.0.5 developed by R Core Team (2021). We use the ML estimate of $(\boldsymbol{\Phi}, \boldsymbol{P}, \boldsymbol{\Lambda}, \boldsymbol{\Gamma})$ for their initial values. ${ }^{17}$ With poor initial values, the restriction that the eigenvalues of $\boldsymbol{A}$ lie inside the unit circle does not hold, and the iteration cannot start. Hence the choice of initial values seems important when one applies the $\mathrm{B}-\mathrm{N}$ decomposition. Once the iteration starts, the restriction rarely binds for our sample.

To check convergence of the Markov chain generated by our Gibbs sampler to its stationary distribution, we perform convergence diagnoses discussed in Robert and Casella (2009, ch. 8) and available in the coda package for R. Given the diagnoses, we discard the initial 1000 draws, and use the next 4000 draws for our posterior inference. At significance level 0.05 , Geweke's Z-score rejects equality of the means of the first 10\% and the last $50 \%$ of the posterior sample (the default choice in the coda package) for 6 out of 141 identified parameters (applying linear normalization to $\boldsymbol{\Gamma}$ ). Since the rejection rate is close to the significance level, 1000 draws are enough as burn-in. The minimum effective sample size among the 141 identified parameters

Table 5: Engle-Granger cointegration tests.

\begin{tabular}{llrr}
\hline LHS & Trend & $\boldsymbol{\tau}$ & $\boldsymbol{p}$-Value \\
\hline$\pi_{t}$ & Yes & -3.79 & 0.21 \\
$\hat{r}_{t}$ & Yes & -3.58 & 0.30 \\
$U_{t}$ & Yes & -3.28 & 0.45 \\
$\Delta \ln Y_{t}$ & Yes & -8.33 & 0.00 \\
\hline$\pi_{t}$ & No & -3.60 & 0.16 \\
$\hat{r}_{t}$ & No & -3.57 & 0.17 \\
$U_{t}$ & No & -3.19 & 0.32 \\
$\Delta \ln Y_{t}$ & No & -7.85 & 0.00 \\
\hline
\end{tabular}

The number of lags included in the ADF regression is 4 (the default value for our sample length in gretl 2021a). 
Table 6: Johansen's cointegration tests (unrestricted constant and restricted trend in the VECM).

\begin{tabular}{lrrrr}
\hline Rank & Trace & $\boldsymbol{p}$-Value & $\lambda$-max & $\boldsymbol{p}$-Value \\
\hline 0 & 142.77 & 0.00 & 83.00 & 0.00 \\
1 & 59.78 & 0.00 & 41.81 & 0.00 \\
2 & 17.97 & 0.35 & 12.00 & 0.43 \\
3 & 5.97 & 0.47 & 5.97 & 0.48 \\
\hline
\end{tabular}

The number of lags included in the VECM is 4 (the default value for our sample length in gretl 2021a).

Table 7: Lag order selection.

\begin{tabular}{lcccccc}
\hline Lag & Log-lik & LR & $p$-Value & AIC & BIC & HQC \\
\hline 1 & 4400.07 & & & -31.71 & -31.40 & -31.58 \\
2 & 4752.06 & 703.98 & 0.00 & -34.15 & $-33.62^{*}$ & -33.93 \\
3 & 4782.56 & 61.01 & 0.00 & -34.25 & -33.52 & $-33.96^{*}$ \\
4 & 4800.35 & 35.58 & 0.00 & -34.26 & -33.32 & -33.88 \\
5 & 4814.33 & 27.96 & 0.03 & -34.25 & -33.09 & -33.79 \\
6 & 4834.26 & 39.87 & 0.00 & -34.28 & -32.91 & -33.73 \\
7 & 4855.60 & 42.67 & 0.00 & $-34.32^{*}$ & -32.74 & -33.68 \\
8 & 4868.15 & 25.10 & 0.07 & -34.29 & -32.51 & -33.58 \\
\hline
\end{tabular}

For AIC, BIC, and HQC, * denotes the selected model. The LR test statistic for testing $H_{0}:\left\{\boldsymbol{y}_{t}\right\} \sim \operatorname{VAR}(p-1)$ versus $H_{1}:\left\{\boldsymbol{y}_{t}\right\} \sim$ $\operatorname{VAR}(p)$ follows $\chi^{2}(16)$ under $H_{0}$.

is 238. Gelman et al. (2014, p. 267) write, ‘... 100 independent draws are enough for reasonable posterior summaries.' Hence 4000 draws are enough for posterior inference.

To select the cointegrating rank, we set $p:=7$, assume the above priors, and compute the S-D density ratios for $r=0$ versus $r=1,2,3$, respectively, from which we derive the posterior probabilities of $r=0,1,2,3$, assuming the flat prior on $r$. We find that the posterior probability of $r=2$ is often numerically 1 , which is consistent with the results of Johansen's cointegration tests. ${ }^{18}$ Thus we set $r:=2$ in the following analysis.

\subsection{Empirical results}

Figure 2 plots the actual rates and our point estimates (posterior medians) of the natural rates (or their permanent components) of the four variables. For ease of comparison of the actual and natural rates, we omit error bands for the natural rates, which are identical to those for the gaps. Figure 3 plots our point estimates of the gaps and their 95\% error bands. Since a VECM has both the level and difference series, to avoid confusion in estimation, we do not annualize quarterly rates. To compare our results with previous works that use annualized quarterly rates, one must multiply our inflation and interest rates by 4 or 400 .

Our estimate of the natural rate of inflation is smoother than typical univariate estimates of trend inflation in the CPI; e.g., Faust and Wright (2013, p. 22). Our estimate looks close to a recent estimate of trend inflation in the US CPI in Morley, Piger, and Rasche (2015, p. 894) based on a bivariate UC model for the inflation

17 The urca package for R is useful for ML estimation of a VECM.

18 The S-D density ratio may be inaccurate if the marginal posterior pdf of $\boldsymbol{\Lambda}$ at $\mathbf{0}_{N \times r}$ is extremely small. In such a case, one should check the result by running the Gibbs sampler multiple times. Wagenmakers et al. (2010, p. 182) write, 'the qualitative conclusion is evident and reliable... even if the quantitative result is not.' 

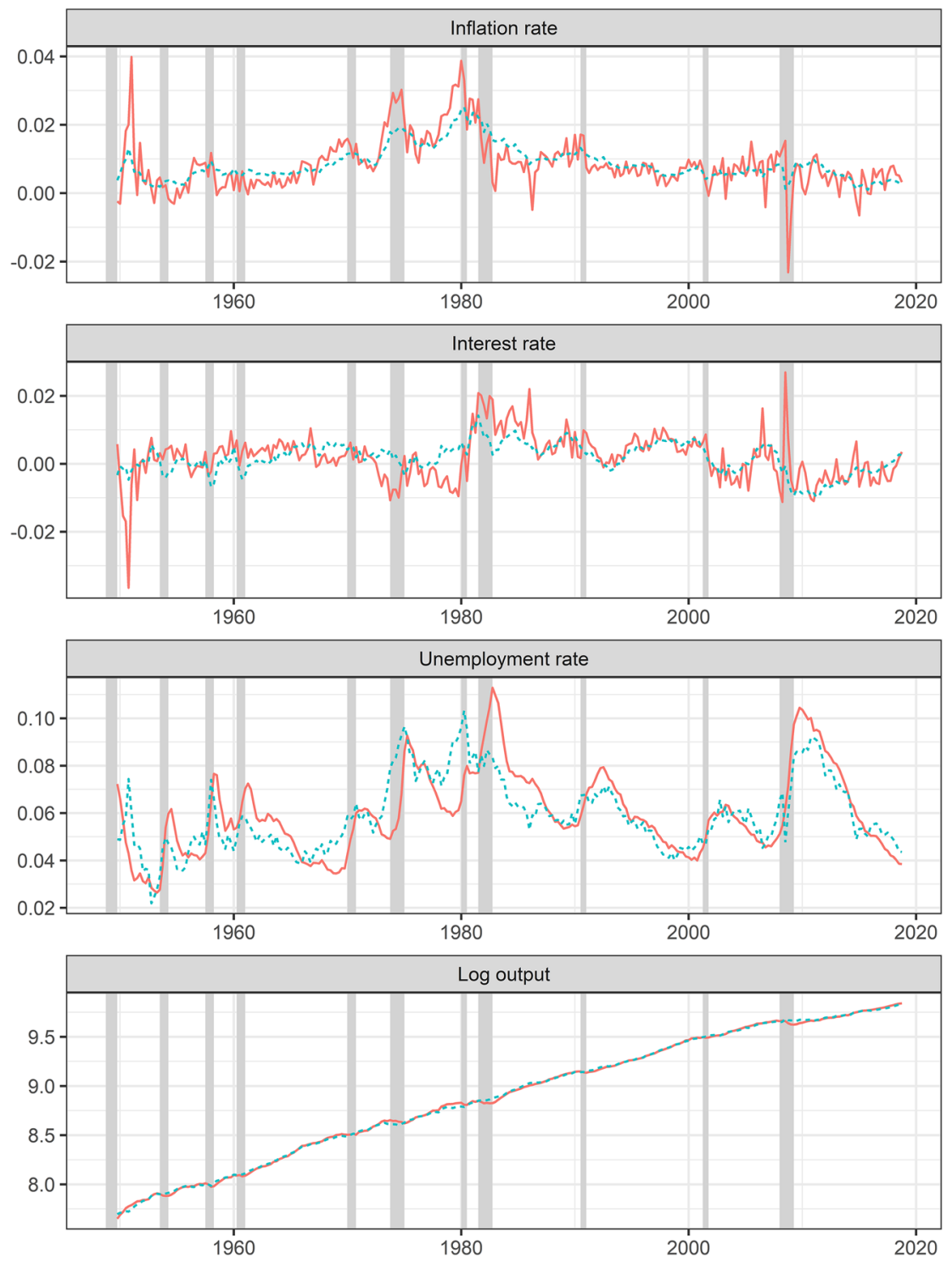

Figure 2: Actual rates (solid red) and the posterior medians of the natural rates (dashed green). The shaded areas are the NBER recessions.

and unemployment rates, which assumes independent shocks to the trend and gap components and allows for structural breaks in the variances of these shocks. Our estimate is more volatile, however, than a recent estimate of trend inflation in the PCE price index by Chan, Clark, and Koop (2018, p. 21) that uses information in survey inflation expectations. Hwu and Kim (2019) estimate trend inflation in the PCE price index using a univariate UC model with correlated shocks to the trend and gap components, Markov-switching gap persistence, and Markov-switching association between inflation and inflation uncertainty. Without the last feature, their estimate looks close to ours; see Hwu and Kim (2019, p. 2314).

Our estimate of the natural rate of interest is more volatile than a recent estimate by Del Negro et al. (2017, p. 237) based on a VAR model with common trends (or a multivariate UC model with independent shocks to the trend and gap components and a factor structure for the trend components) for short- and longterm interest rates, inflation and its survey expectations, and some other variables. Their estimate is smooth partly because they impose tight priors on the variances of the shocks to the trend components. 

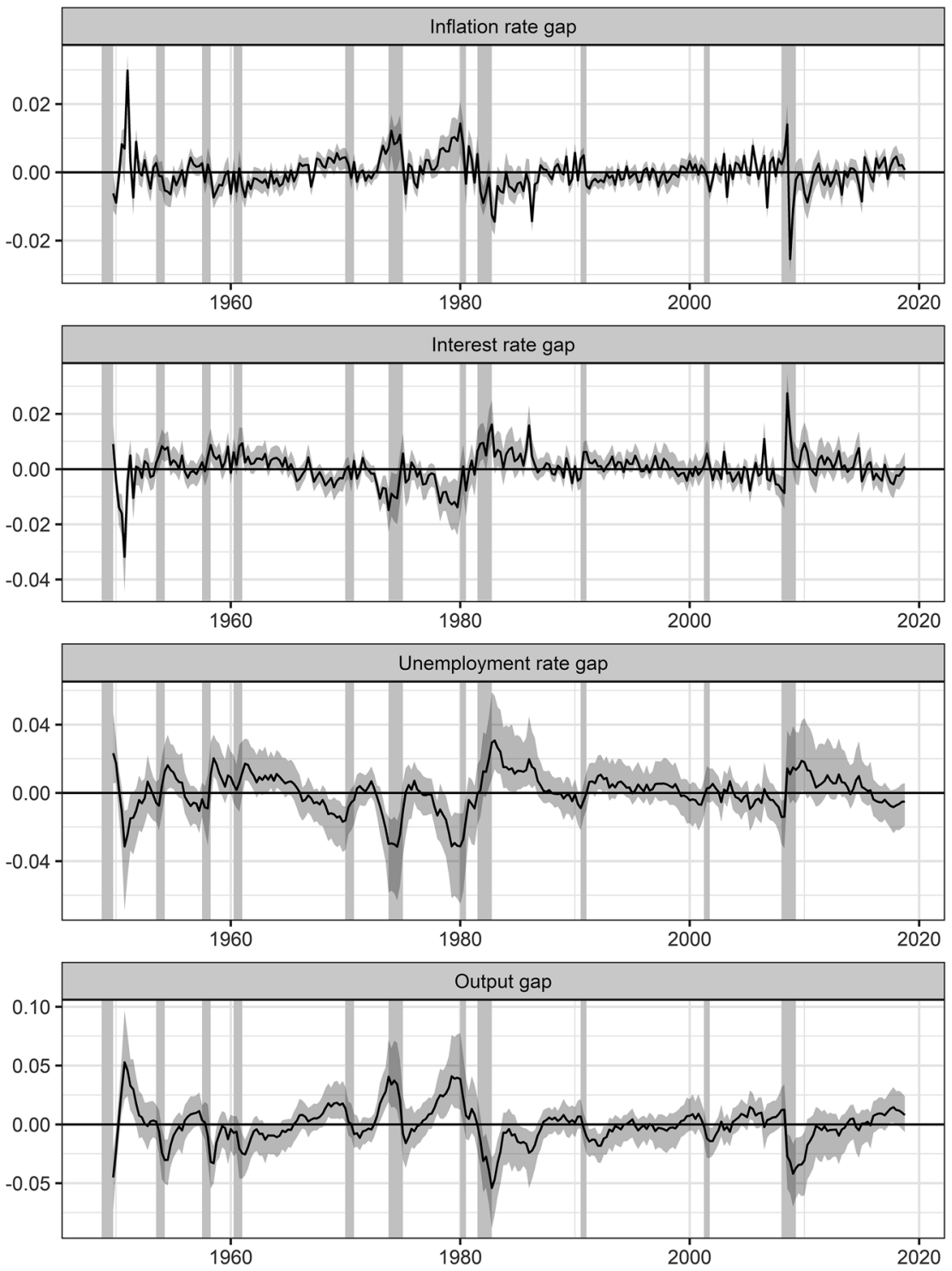

Figure 3: Posterior medians of the gaps and their $95 \%$ error bands (posterior 0.025- and 0.975-quantiles). The shaded areas are the NBER recessions.

With the 'loosest possible prior', their estimate is as volatile as ours; see Del Negro et al. (2017, p. 272). ${ }^{19}$ Despite different definitions of the natural rate, their estimate based on a DSGE model looks close to ours; see Del Negro et al. (2017, p. 237). ${ }^{20}$ Estimates by Laubach and Williams (2016, p. 60), Holston, Laubach, and Williams (2017, p. S61), and Lewis and Vazquez-Grande (2019) are close to trend output growth by construction; hence their estimates are quite different from those by Del Negro et al. (2017) and ours, especially before $1980 .{ }^{21}$

19 Their 'loosest possible prior' on the variance-covariance matrix of the shocks to the trend components is an inverse Wishart prior with the minimum degree of freedom that gives a finite mean; see Del Negro et al. (2017, p. 271 ).

20 Del Negro et al. (2017) clearly distinguish the natural rate and its low-frequency component, estimating the former by a DSGE model and the latter by a VAR model. To construct the real interest rate, they use the PCE inflation rate instead of the CPI inflation rate; hence their real interest rate is on average slightly higher than ours.

21 Holston, Laubach, and Williams (2017, p. S63) writes, 
Our estimate of the natural rate of unemployment looks more volatile than a recent estimate by Morley, Piger, and Rasche (2015, p. 898), obtained as a by-product of estimation of trend inflation. A possible reason for the difference is that they assume independent shocks to the trend and gap components, which may not hold in practice. The two estimates may coincide if one allows for dependence between the shocks, as Morley, Nelson, and Zivot (2003) show for the univariate trend-cycle decomposition. Despite the difference in volatility, our estimate of the unemployment rate gap looks close to that by Morley, Piger, and Rasche (2015, p. 901) in terms of the sign and magnitude. Recent estimates of the natural rate and gap by Crump et al. (2019, pp. 176, 180) are as smooth as those by Morley, Piger, and Rasche (2015), perhaps partly because they also assume independent shocks to the trend and gap components. ${ }^{22}$

Our estimate of the output gap is at most about $\pm 5 \%$ of the output level, and looks close to a recent estimate by Morley and Wong (2020, p. 9) based on a large Bayesian VAR(4) model with 23 variables. Our estimate also looks close to their estimate based on a Bayesian VAR(4) model with four variables using output growth, the unemployment rate, the CPI inflation rate, and the growth rate of industrial production, assuming that they are all I(0); see Morley and Wong (2020, p. 8). Though output growth may or may not be I(0) in the US, it may be clearly I(1) in some countries or regions, in which case their method may give an unreasonable estimate of the output gap with a strong upward or downward trend, as Murasawa (2015) shows for the Japanese data.

Figure 4 plots the posterior probability of positive gap for the four variables. This probability index is useful if the sign of the gap is of interest. Even if the $95 \%$ error band for the gap covers 0 , the posterior probability of positive gap may be close to 0.025 or 0.975 . Indeed, the probability index is often below 0.25 or above 0.75 ; hence we are often quite sure about the sign of the gap. Moreover, Figure 4 shows the relation between the gaps more clearly than Figure 3.

Figure 5 shows the relation between the gaps more directly. The left panels are the scatter plots of the posterior medians of the gaps in each quarter. The right panels are the posterior pdfs of the correlation coefficients between the gaps. We see that the Phillips curves and Okun's law hold between the gaps, though we do not impose such relations. Thus our estimates of the gaps seem mutually consistent from a macroeconomic point of view.

Figure 6 shows the relation between the trend output growth rate $\Delta \ln Y_{t+1}^{*}$ and the natural rate of interest $r_{t}^{*}$, i.e., the dynamic IS curve; see Eq. (1). The left panel is the scatter plot of the posterior medians of $\Delta \ln Y_{t+1}^{*}$ and $r_{t}^{*}$ in each quarter. The right panel is the posterior pdf of the slope coefficient, i.e., $1 / \sigma$ in Eq. (1), obtained by regressing $\Delta \ln Y_{t+1}^{*}$ on $r_{t}^{*}$ for each posterior draw of $\left\{\Delta \ln Y_{t}^{*}, r_{t}^{*}\right\}$. On average, the slope is positive as expected, but the evidence is weak. The result is similar to Hamilton et al. (2016) and Lunsford and West (2019), who study the determinants of $r_{t}^{*}$ and find positive but low and insignificant long-run correlations between $\Delta \ln Y_{t}$ and $r_{t}$ in the postwar US.

... we assume a one-for-one relationship between the trend growth rate of output and the natural rate of interest, which corresponds to assuming $\sigma=1 \mathrm{in} \mathrm{Eq.} \mathrm{(1).}$

where Eq. (1) in their paper is the consumption Euler equation in a steady state.

22 Crump et al. (2019) distinguish the trend unemployment rate $\bar{u}$ and the natural rate of unemployment $u^{*}$. They construct $\bar{u}$ from estimates of the trend job separation and finding rates based on a multivariate UC model with a factor structure for the rates across demographic groups, assuming independent shocks to the trend and gap components. Treating $\bar{u}$ as exogenous and relying on a New Keynesian (wage) Phillips curve, they estimate $u^{*}$ using the CPI, survey inflation expectations, and various wage data, again assuming independent shocks to the natural rate and gap. Allowing for dependence between these shocks seems an interesting and important topic for future work. 

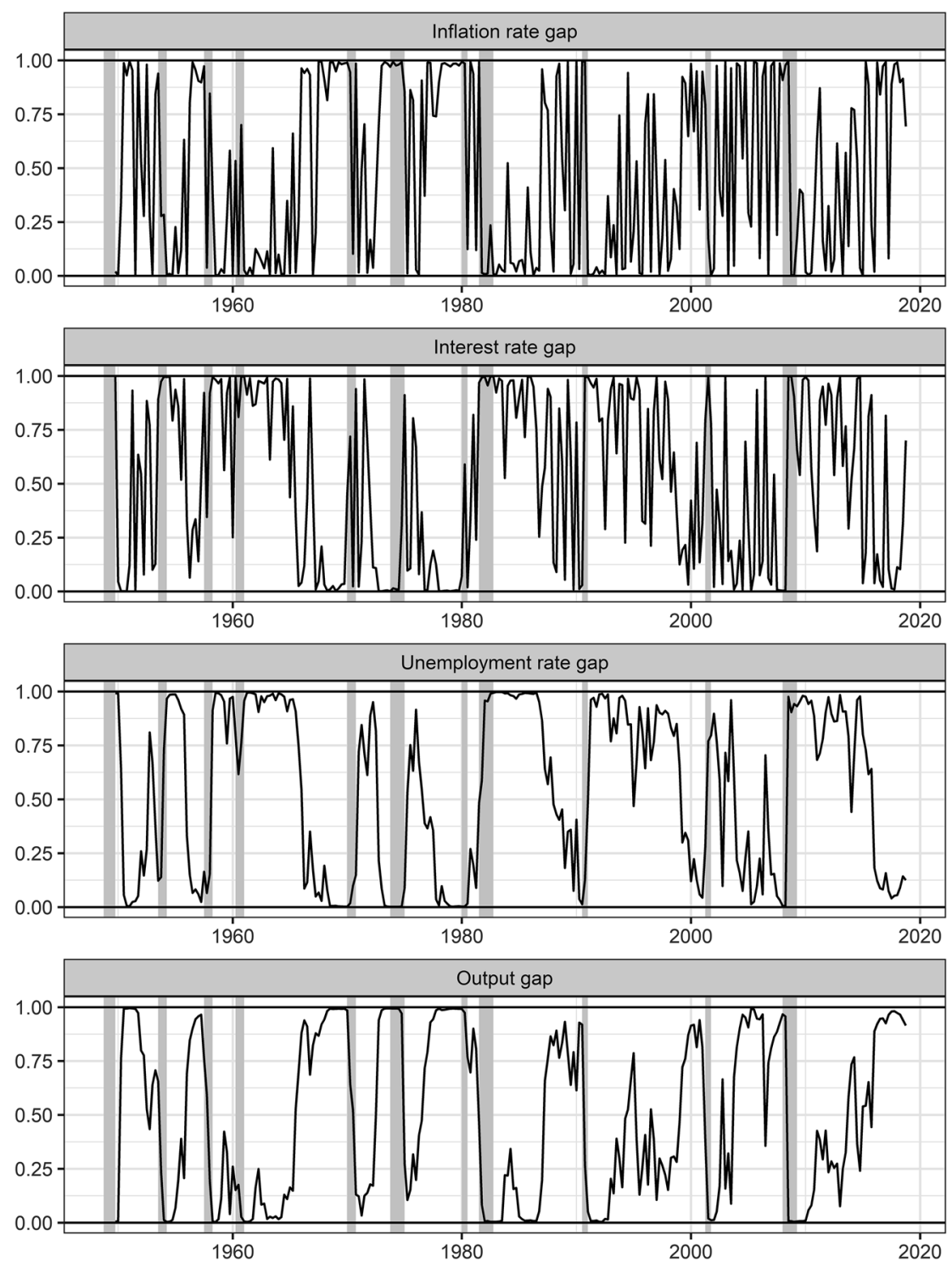

Figure 4: Posterior probability of positive gap. The shaded areas are the NBER recessions.

\subsection{Comparison of alternative model specifications}

Figure 7 compares point estimates of the gaps under three alternative assumptions, i.e., I(1) log output, I(2) $\log$ output with no cointegration, and I(2) log output with cointegration..$^{23}$ For ease of comparison, we omit error bands here.

The result assuming I(1) log output is similar to that in Murasawa (2014, p. 513), who assumes a VAR(12) model with no constant term for the centered stationarized series, and chooses the tightness hyperparameter by the empirical Bayes method. In contrast to the result for Japan in Figure 1, for the US, the multivariate B-N decomposition assuming I(1) log output gives a 'reasonable' estimate of the output gap that fluctuates around 0 . However, the output gap is persistently positive since 2010, which may not be sensible.

Assuming I(2) log output changes the estimate of the output gap. However, it hardly changes the estimates of other gaps, similar to the result for Japan in Murasawa (2015), which makes sense because the B-N transitory

23 For the first two cases with no cointegration, we assume $\operatorname{VAR}(7)$ models for the stationarized series, and use the same prior and Gibbs sampler as those for our VECM (except for the loading and cointegrating matrices). 

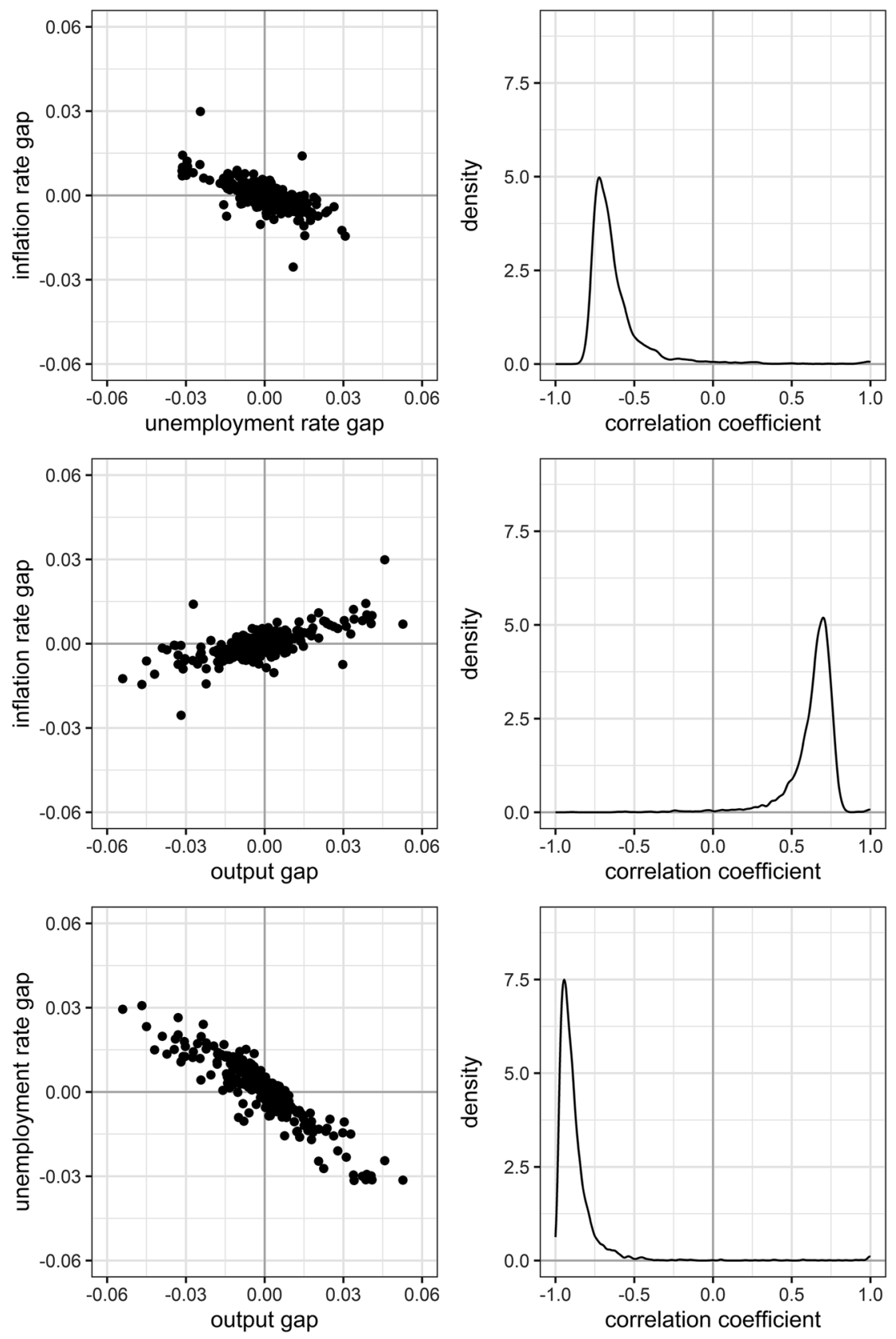

Figure 5: Phillips curves and Okun's law. The left panels are the scatter plots of the posterior medians of the gaps in each quarter. The right panels are the posterior pdfs of the correlation coefficients between the gaps.

components are 'forecastable movements', and whether log output is I(1) or I(2), the two VAR models use the information in log output for forecasting other variables in almost the same way. ${ }^{24}$ The output gap now keeps fluctuating around 0 since 2010, perhaps because I(2) log output captures a possible structural break in the mean output growth rate after the 2008 Great Recession.

Allowing for cointegration gives much bigger estimates of the gaps for all variables. The result follows partly because a VECM uses more predictors, i.e., the error correction terms, than a VAR model; see

$24 \mathrm{~A} \operatorname{VAR}(p)$ model with $\left\{\Delta^{2} \ln Y_{t}\right\}$ includes $\Delta^{2} \ln Y_{t-p}:=\Delta \ln Y_{t-p}-\Delta \ln Y_{t-p-1}$ as a predictor and hence use the information in $\Delta \ln Y_{t-p-1}$, but a $\operatorname{VAR}(p)$ model with $\left\{\Delta \ln Y_{t}\right\}$ does not. If $p$ is large enough, then the coefficient on $\Delta \ln Y_{t-p-1}$ tends to be small, especially with our shrinkage prior on the VAR coefficients. 

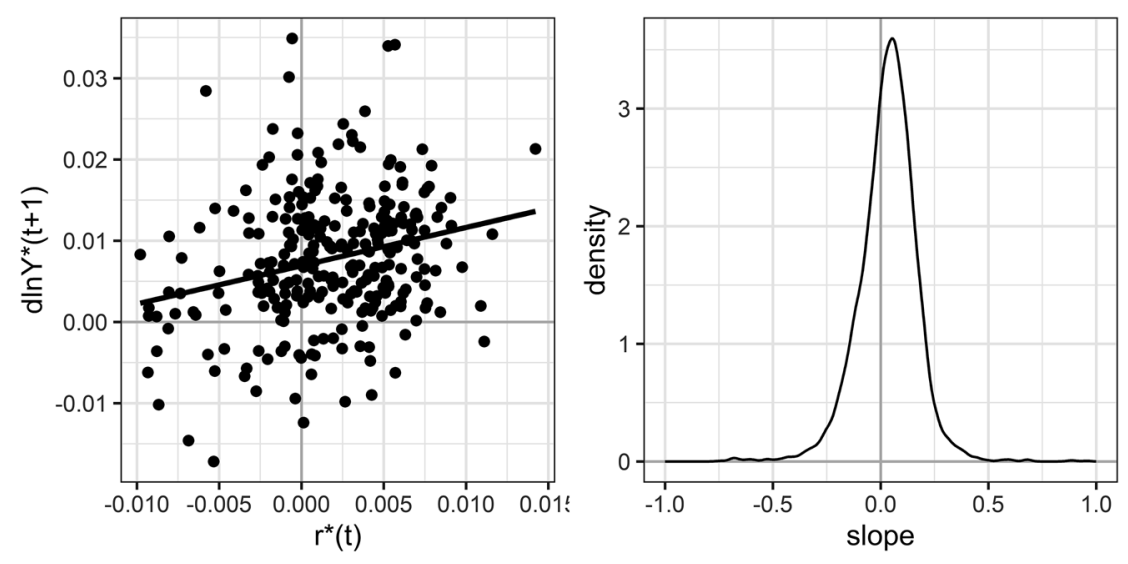

Figure 6: Dynamic IS curve. The left panel is the scatter plot of the posterior medians of $\Delta \ln Y_{t+1}^{*}$ and $r_{t}^{*}$ in each quarter. The right panel is the posterior pdf of the slope coefficient obtained by regressing $\Delta \ln Y_{t+1}^{*}$ on $r_{t}^{*}$ for each posterior draw of $\left\{\Delta \ln Y_{t}^{*}, r_{t}^{*}\right\}$.

Evans and Reichlin (1994). However, the result also implies that for all variables, the coefficients on the error correction terms are large enough, if not significantly different from 0 , to obtain such different estimates of the gaps. These bigger estimates of the gaps, or the associated estimates of the natural rates, are often close to other recent estimates that focus on a particular natural rate or gap, as already noted.

\section{Discussion}

The dynamic IS equation implies that if the real interest rate is I(1), then so is the output growth rate with possible cointegration, and log output is I(2). We extend the multivariate $\mathrm{B}-\mathrm{N}$ decomposition to such a case, and apply Bayesian analysis to obtain error bands for the components. To implement this idea, we consider a steady state VECM with a hierarchical prior on the VAR coefficients, and develop a Gibbs sampler for posterior simulation of the parameters and the components. Applying the method to US data with weakly informative priors, we obtain a reasonable joint estimate of the natural rates (or their permanent components) and gaps of output, inflation, interest, and unemployment.

The $\mathrm{B}-\mathrm{N}$ decomposition assuming I(1) log output may give a trending estimate of the output gap if the mean output growth rate has structural breaks. Assuming I(2) log output and hence I(1) output growth rate, we introduce a stochastic trend in the output growth rate, which captures possible structural breaks in the mean output growth rate. Thus the B-N decomposition assuming I(2) log output gives a reasonable estimate of the output gap that fluctuates around 0 . Since the $\mathrm{B}-\mathrm{N}$ transitory components are 'forecastable movements', and a VECM forecasts no worse than a VAR model, allowing for cointegration gives larger estimates of the gaps for all variables. Since we can treat an I(0) series as an I(1) series cointegrated with itself, our method is valid even if the output growth rate is I(0), or log output is I(1).

The $\mathrm{B}-\mathrm{N}$ decomposition has some advantages over other approaches:

1. The $\mathrm{B}-\mathrm{N}$ decomposition relies on a reduced-form forecasting model; hence it requires fewer assumptions than the decomposition based on a structural model.

2. The $\mathrm{B}-\mathrm{N}$ decomposition requires no state smoothing if the state vector is observable as in our VECM; hence it can handle a large state vector more easily than the decomposition based on a UC model, which involves latent variables.

Thus the multivariate $\mathrm{B}-\mathrm{N}$ decomposition is useful for estimating the natural rates and gaps of many variables jointly. Most, if not all, previous works focus on the natural rate or gap of one variable, using other variables only to improve estimation. We estimate the natural rates and gaps of four variables, which are equally of interest.

Since a reduced-form VECM is the most basic forecasting model for cointegrated series, our method gives a benchmark joint estimate of the natural rates and gaps of major macroeconomic variables. One can compare 

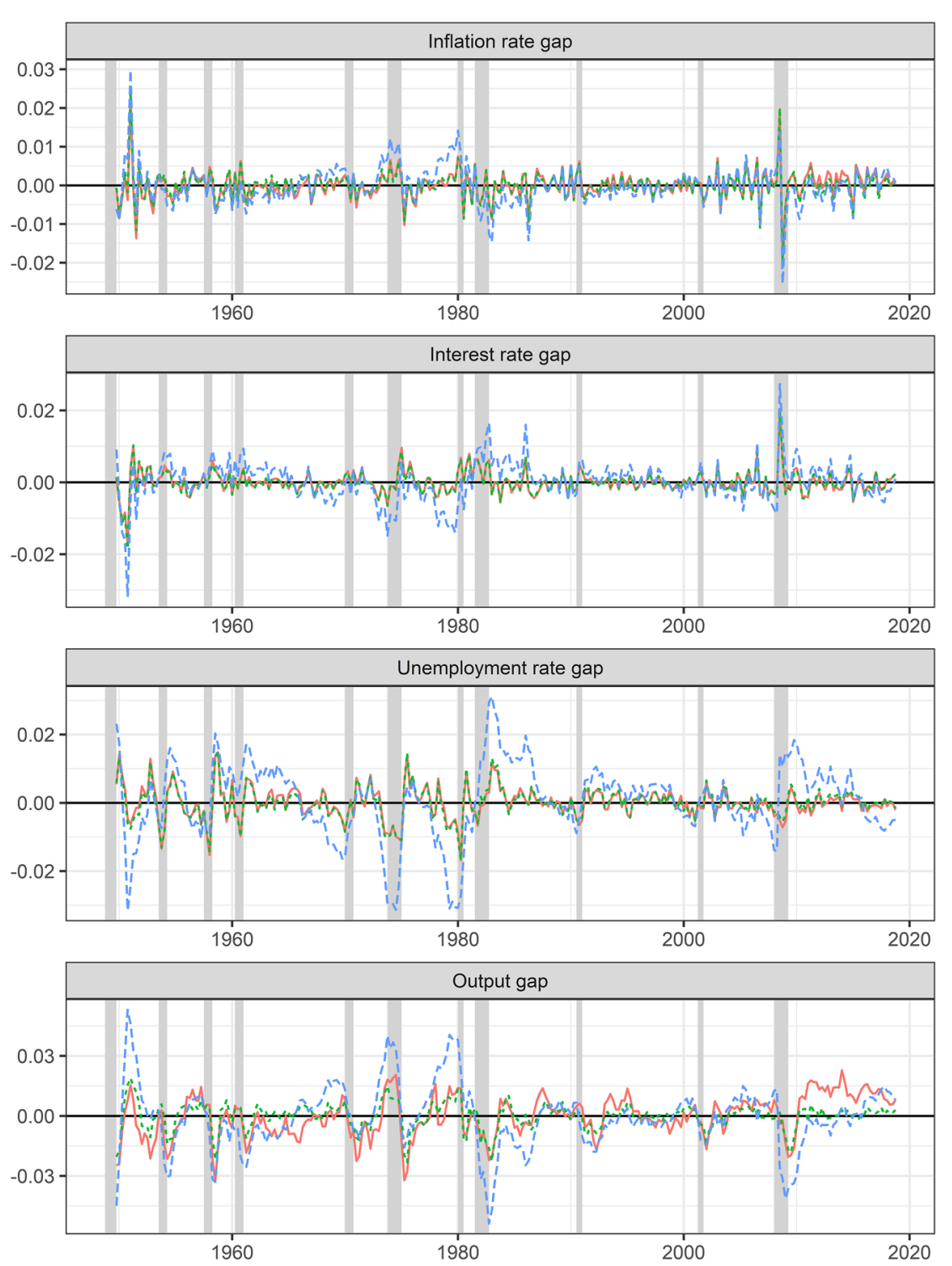

Figure 7: Posterior medians of the gaps assuming I(1) log output (solid red), I(2) log output with no cointegration (dashed green), and I(2) log output with cointegration (longdash blue). The shaded areas are the NBER recessions.

this benchmark estimate with alternative estimates based on other forecasting models or DSGE models such as those in Del Negro et al. (2017). Our method is useful especially for non-US data, where log output is often clearly I(2). Application to non-US data is an interesting and important topic for future work.

One can possibly refine our estimate in two ways. First, one can use a larger VECM. Second, one can introduce nonlinearity into our VECM; e.g., Markov-switching, stochastic volatility, or more general timevarying parameters. Since the B-N decomposition may not apply to nonlinear models, and nonlinear models may become unnecessary with more variables, the first direction seems more promising. The following four variables are of particular interest:

1. PCE price index in addition to the CPI, which makes our results comparable to various previous works that use whichever price index.

2. long-run (LR) interest rate in addition to the short-run (SR) interest rate, which gives an estimate of the trend term premium, or the natural yield curve; cf. Brzoza-Brzezina and Kotłowski (2014) and Imakubo, Kojima, and Nakajima (2018)

3. nominal yields on Aaa and Baa corporate bonds, which give estimates of the trend liquidity premium and the trend safety premium, or the trend liquidity and safety convenience yields; cf. Del Negro et al. (2017) 
Our VECM allows for cointegration among I(1) series, but does not allow for cointegration among I(2) series nor multicointegration (polynomial cointegration). Such extensions are useful if we have multiple I(2) series; e.g., $\log$ output and the price level (instead of the inflation rate). We leave such extensions for future work.

Lastly, to obtain a monthly instead of quarterly joint estimate of the natural rates and gaps of output and other variables, it seems straightforward to extend the $\mathrm{B}-\mathrm{N}$ decomposition of mixed-frequency series proposed by Murasawa (2016) to I(1) and I(2) series with cointegration.

Acknowledgement: I thank Roberto León-González for pointing out errors in an earlier draft. I also thank a referee, Marco Del Negro, and Pierre-Alain Pionnier for helpful comments.

Author contribution: The author has accepted responsibility for the entire content of this submitted manuscript and approved submission.

Research funding: This work was supported by JSPS KAKENHI Grant Number JP16K03605.

Conflict of interest statement: The author declares no conflicts of interest regarding this article.

\section{A. Appendix: Gibbs sampler}

\section{A.1 Useful lemmas}

Our Gibbs sampler relies on the following two familiar results in Bayesian analysis of normal linear models, which we state as lemmas for ease of reference.

Lemma 1. Suppose that

$$
\begin{aligned}
& \boldsymbol{y}=\boldsymbol{X} \boldsymbol{\beta}+\boldsymbol{u} \\
& \boldsymbol{u} \sim \mathrm{N}_{n}\left(\mathbf{0}_{n}, \boldsymbol{P}^{-1}\right)
\end{aligned}
$$

and

$$
\boldsymbol{\beta} \mid \boldsymbol{P} \sim \mathrm{N}_{k}\left(\boldsymbol{\mu}_{0}, \boldsymbol{D}_{0}^{-1}\right)
$$

Then

$$
\boldsymbol{\beta} \mid \boldsymbol{P}, \boldsymbol{y}, \boldsymbol{X} \sim \mathrm{N}_{k}\left(\boldsymbol{\mu}_{1}, \boldsymbol{D}_{1}^{-1}\right)
$$

where

$$
\begin{aligned}
& \boldsymbol{D}_{1}:=\boldsymbol{X}^{\prime} \boldsymbol{P} \boldsymbol{X}+\boldsymbol{D}_{0} \\
& \boldsymbol{\mu}_{1}:=\boldsymbol{D}_{1}^{-1}\left(\boldsymbol{X}^{\prime} \boldsymbol{P} \boldsymbol{X} \boldsymbol{b}_{\mathrm{GLS}}+\boldsymbol{D}_{0} \boldsymbol{\mu}_{0}\right)
\end{aligned}
$$

with $\boldsymbol{b}_{\mathrm{GLS}}:=\left(\boldsymbol{X}^{\prime} \boldsymbol{P X}\right)^{-1} \boldsymbol{X}^{\prime} \boldsymbol{P} \boldsymbol{y}$

Proof. See Koop (2003, pp. 118-121).

Lemma 2. Suppose that

$$
\begin{aligned}
& \boldsymbol{Y}=\boldsymbol{X} \boldsymbol{B}^{\prime}+\boldsymbol{U} \\
& \boldsymbol{U} \sim \mathrm{N}_{n \times m}\left(\mathbf{0}_{n \times m} ; \boldsymbol{I}_{n}, \boldsymbol{P}^{-1}\right)
\end{aligned}
$$

and

$$
\begin{aligned}
\boldsymbol{B} \mid \boldsymbol{P} & \sim \mathrm{N}_{m \times k}\left(\boldsymbol{M}_{0} ; \boldsymbol{P}^{-1}, \boldsymbol{D}_{0}^{-1}\right) \\
\boldsymbol{P} & \sim \mathrm{W}_{m}\left(k_{0} ; \boldsymbol{S}_{0}^{-1}\right)
\end{aligned}
$$


Then

$$
\begin{aligned}
\boldsymbol{B} \mid \boldsymbol{P}, \boldsymbol{Y}, \boldsymbol{X} & \sim \mathrm{N}_{m \times k}\left(\boldsymbol{M}_{1} ; \boldsymbol{P}^{-1}, \boldsymbol{D}_{1}^{-1}\right) \\
\boldsymbol{P} \mid \boldsymbol{Y}, \boldsymbol{X} & \sim \mathrm{W}_{m}\left(k_{1} ; \boldsymbol{S}_{1}^{-1}\right)
\end{aligned}
$$

where

$$
\begin{aligned}
\boldsymbol{D}_{1} & :=\boldsymbol{X}^{\prime} \boldsymbol{X}+\boldsymbol{D}_{0} \\
\boldsymbol{M}_{1} & :=\left(\boldsymbol{B}_{\mathrm{OLS}} \boldsymbol{X}^{\prime} \boldsymbol{X}+\boldsymbol{M}_{0} \boldsymbol{D}_{0}\right) \boldsymbol{D}_{1}^{-1} \\
k_{1} & :=n+k_{0} \\
\boldsymbol{S}_{1} & :=\left(\boldsymbol{B}_{\mathrm{OLS}}-\boldsymbol{M}_{0}\right)\left[\left(\boldsymbol{X}^{\prime} \boldsymbol{X}\right)^{-1}+\boldsymbol{D}_{0}^{-1}\right]^{-1}\left(\boldsymbol{B}_{\mathrm{OLS}}-\boldsymbol{M}_{0}\right)^{\prime}+\boldsymbol{S}+\boldsymbol{S}_{0}
\end{aligned}
$$

with $\boldsymbol{B}_{\mathrm{OLS}}:=\boldsymbol{Y}^{\prime} \boldsymbol{X}\left(\boldsymbol{X}^{\prime} \boldsymbol{X}\right)^{-1}$ and $\boldsymbol{S}:=\left(\boldsymbol{Y}-\boldsymbol{X} \boldsymbol{B}_{\mathrm{OLS}}^{\prime}\right)^{\prime}\left(\boldsymbol{Y}-\boldsymbol{X} \boldsymbol{B}_{\mathrm{OLS}}^{\prime}\right)$.

Proof. See Drèze and Richard (1983, pp. 539-541).

\section{A.2 Steady state parameters}

Write the VECM as for all $t$,

$$
\Phi(\mathrm{L}) \Delta \boldsymbol{y}_{t}-\Phi(1) \boldsymbol{\mu}=-\Lambda\left[\Gamma^{\prime} \boldsymbol{y}_{t-1}-\boldsymbol{\beta}-\Gamma^{\prime} \boldsymbol{\mu}(t-1)\right]+\boldsymbol{u}_{t}
$$

or

$$
\Phi(\mathrm{L}) \Delta \boldsymbol{y}_{t}+\Lambda \Gamma^{\prime} \boldsymbol{y}_{t-1}=\Lambda \boldsymbol{\beta}+\left[\Phi(1)+(t-1) \Lambda \Gamma^{\prime}\right] \boldsymbol{\mu}+\boldsymbol{u}_{t}
$$

Let for all $t$,

$$
\begin{aligned}
\boldsymbol{w}_{t} & :=\Phi(\mathrm{L}) \Delta \boldsymbol{y}_{t}+\Lambda \Gamma^{\prime} \boldsymbol{y}_{t-1} \\
\boldsymbol{z}_{t} & :=\left[\begin{array}{ll}
\Lambda & \Phi(1)+(t-1) \Lambda \Gamma^{\prime}
\end{array}\right]
\end{aligned}
$$

Then for all $t$,

$$
\boldsymbol{w}_{t}=\boldsymbol{Z}_{t} \boldsymbol{\psi}+\boldsymbol{u}_{t}
$$

Let

$$
\boldsymbol{w}:=\left(\begin{array}{c}
\boldsymbol{w}_{p+1} \\
\vdots \\
\boldsymbol{w}_{T}
\end{array}\right), \quad \boldsymbol{Z}:=\left[\begin{array}{c}
\boldsymbol{Z}_{p+1} \\
\vdots \\
\boldsymbol{Z}_{T}
\end{array}\right], \quad \boldsymbol{u}:=\left(\begin{array}{c}
\boldsymbol{u}_{p+1} \\
\vdots \\
\boldsymbol{u}_{T}
\end{array}\right)
$$

Then we have a normal linear model for $\boldsymbol{w}$ given $\boldsymbol{Z}$ such that

$$
\begin{aligned}
& \boldsymbol{w}=\boldsymbol{Z} \boldsymbol{\psi}+\boldsymbol{u} \\
& \boldsymbol{u} \sim \mathrm{N}_{N(T-p)}\left(\mathbf{0}_{N(T-p)}, \boldsymbol{I}_{T-p} \otimes \boldsymbol{P}^{-1}\right)
\end{aligned}
$$

Theorem 2. Suppose that

$$
\boldsymbol{\psi} \mid \boldsymbol{\Phi}, \boldsymbol{P}, \Lambda, \Gamma \sim \mathrm{N}_{r+N}\left(\boldsymbol{\psi}_{0}, \boldsymbol{Q}_{0}^{-1}\right)
$$

Then

$$
\boldsymbol{\psi} \mid \boldsymbol{\Phi}, \boldsymbol{P}, \Lambda, \Gamma, \boldsymbol{w} \sim \mathrm{N}_{r+N}\left(\boldsymbol{\psi}_{1}, \boldsymbol{Q}_{1}^{-1}\right)
$$

where

$$
\boldsymbol{Q}_{1}:=\boldsymbol{Z}^{\prime}\left(\boldsymbol{I}_{T-p} \otimes \boldsymbol{P}\right) \boldsymbol{Z}+\boldsymbol{Q}_{0}
$$




$$
\boldsymbol{\psi}_{1}=\boldsymbol{Q}_{1}^{-1}\left[\boldsymbol{Z}^{\prime}\left(\boldsymbol{I}_{T-p} \otimes P\right) \boldsymbol{w}+\boldsymbol{Q}_{0} \boldsymbol{\Psi}_{0}\right]
$$

Proof. Let $\boldsymbol{\psi}_{\mathrm{GLS}}$ be the GLS estimator of $\boldsymbol{\psi}$, i.e.,

$$
\boldsymbol{\psi}_{\mathrm{GLS}}=\left[\boldsymbol{Z}^{\prime}\left(\boldsymbol{I}_{T-p} \otimes \boldsymbol{P}\right) \boldsymbol{Z}\right]^{-1} \boldsymbol{Z}^{\prime}\left(\boldsymbol{I}_{T-p} \otimes \boldsymbol{P}\right) \boldsymbol{w}
$$

By Lemma 1,

$$
\begin{aligned}
\boldsymbol{Q}_{1} & :=\boldsymbol{Z}^{\prime}\left(\boldsymbol{I}_{T-p} \otimes \boldsymbol{P}\right) \boldsymbol{Z}+\boldsymbol{Q}_{0} \\
\boldsymbol{\psi}_{1} & :=\boldsymbol{Q}_{1}^{-1}\left[\boldsymbol{Z}^{\prime}\left(\boldsymbol{I}_{T-p} \otimes \boldsymbol{P}\right) \boldsymbol{Z} \boldsymbol{\psi}_{\mathrm{GLS}}+\boldsymbol{Q}_{0} \boldsymbol{\psi}_{0}\right]
\end{aligned}
$$

where

$$
\boldsymbol{Z}^{\prime}\left(\boldsymbol{I}_{T-p} \otimes \boldsymbol{P}\right) \boldsymbol{Z} \boldsymbol{\psi}_{\mathrm{GLS}}=\boldsymbol{Z}^{\prime}\left(\boldsymbol{I}_{T-p} \otimes \boldsymbol{P}\right) \boldsymbol{w}
$$

\section{A.3 VAR parameters}

Let for all $t$,

$$
\boldsymbol{e}_{t}:=\Gamma^{\prime} \boldsymbol{y}_{t}-\boldsymbol{\beta}-\delta t, \quad \boldsymbol{s}_{t}^{*}:=\left(\begin{array}{c}
\Delta \boldsymbol{y}_{t}-\boldsymbol{\mu} \\
\vdots \\
\Delta \boldsymbol{y}_{t-p+1}-\mu
\end{array}\right)
$$

Write the VECM as for all $t$,

$$
\Delta y_{t}-\mu+\Lambda e_{t-1}=\Phi s_{t-1}^{*}+u_{t}
$$

Let

$$
\boldsymbol{Y}_{*}:=\left[\begin{array}{c}
\left(\Delta \boldsymbol{y}_{p+1}-\boldsymbol{\mu}+\Lambda \boldsymbol{e}_{p}\right)^{\prime} \\
\vdots \\
\left(\Delta \boldsymbol{y}_{T}-\boldsymbol{\mu}+\Lambda \boldsymbol{e}_{T-1}\right)^{\prime}
\end{array}\right], \quad \boldsymbol{X}:=\left[\begin{array}{c}
\boldsymbol{s}_{p}^{* \prime} \\
\vdots \\
\boldsymbol{s}_{T-1}^{* \prime}
\end{array}\right], \quad \boldsymbol{U}:=\left[\begin{array}{c}
\boldsymbol{u}_{p+1}^{\prime} \\
\vdots \\
\boldsymbol{u}_{T}^{\prime}
\end{array}\right]
$$

Then we have a normal linear model for $\boldsymbol{Y}_{*}$ given $\boldsymbol{X}$ such that

$$
\begin{aligned}
\boldsymbol{Y}_{*} & =\boldsymbol{X} \Phi^{\prime}+\boldsymbol{U} \\
\boldsymbol{U} & \sim \mathrm{N}_{(T-p) \times N}\left(\mathbf{0}_{(T-p) \times N} ; \boldsymbol{I}_{T-p}, \boldsymbol{P}^{-1}\right)
\end{aligned}
$$

Let $\boldsymbol{\Phi}_{\mathrm{OLS}}:=\boldsymbol{Y}_{*}^{\prime} \boldsymbol{X}\left(\boldsymbol{X}^{\prime} \boldsymbol{X}\right)^{-1}$ and $\boldsymbol{S}:=\left(\boldsymbol{Y}_{*}-\mathbf{X} \boldsymbol{\Phi}_{\mathrm{OLS}}^{\prime}\right)^{\prime}\left(\boldsymbol{Y}_{*}-\mathbf{X} \boldsymbol{\Phi}_{\mathrm{OLS}}^{\prime}\right)$.

Theorem 3. Suppose that

$$
\begin{aligned}
\boldsymbol{\Phi} \mid \boldsymbol{P}, \boldsymbol{\psi}, \Lambda, \Gamma, \nu & \sim \mathrm{N}_{N \times \mathrm{p} N}\left(\boldsymbol{M}_{0} ; \boldsymbol{P}^{-1},\left(\nu \boldsymbol{D}_{0}\right)^{-1}\right) \\
\boldsymbol{P} \mid \boldsymbol{\psi}, \Lambda, \Gamma, \nu & \sim \mathrm{W}_{N}\left(k_{0} ; \boldsymbol{S}_{0}^{-1}\right)
\end{aligned}
$$

Then

$$
\begin{gathered}
\boldsymbol{\Phi} \mid \boldsymbol{P}, \boldsymbol{\psi}, \Lambda, \Gamma, \nu, \boldsymbol{Y}_{*}, \boldsymbol{X} \sim \mathrm{N}_{N \times \mathrm{pN}}\left(\boldsymbol{M}_{1} ; \boldsymbol{P}^{-1}, \boldsymbol{D}_{1}^{-1}\right) \\
\boldsymbol{P} \mid \boldsymbol{\psi}, \Lambda, \Gamma, \nu, \boldsymbol{Y}_{*}, \boldsymbol{X} \sim \mathrm{W}_{N}\left(k_{1} ; \boldsymbol{S}_{1}^{-1}\right)
\end{gathered}
$$

where

$$
\begin{aligned}
\boldsymbol{D}_{1} & :=\boldsymbol{X}^{\prime} \boldsymbol{X}+v \boldsymbol{D}_{0} \\
\boldsymbol{M}_{1} & :=\left(\Phi_{\mathrm{OLS}} \boldsymbol{X}^{\prime} \boldsymbol{X}+\boldsymbol{M}_{0} \nu \boldsymbol{D}_{0}\right) \boldsymbol{D}_{1}^{-1} \\
k_{1} & :=T-p+k_{0}
\end{aligned}
$$




$$
\boldsymbol{S}_{1}:=\left(\boldsymbol{\Phi}_{\mathrm{OLS}}-\boldsymbol{M}_{0}\right)\left[\left(\boldsymbol{X}^{\prime} \boldsymbol{X}\right)^{-1}+\left(\nu \boldsymbol{D}_{0}\right)^{-1}\right]^{-1}\left(\boldsymbol{\Phi}_{\mathrm{OLS}}-\boldsymbol{M}_{0}\right)^{\prime}+\boldsymbol{S}+\boldsymbol{S}_{0}
$$

Proof. Apply Lemma 2.

\section{A.4 Loading matrix}

Write the VECM as for all $t$,

$$
\Phi(\mathrm{L})\left(\Delta \boldsymbol{y}_{t}-\boldsymbol{\mu}\right)=-\Lambda \boldsymbol{e}_{t-1}+\boldsymbol{u}_{t}
$$

Let

$$
\boldsymbol{W}:=\left[\begin{array}{c}
{\left[\Phi(\mathrm{L})\left(\Delta \boldsymbol{y}_{p+1}-\boldsymbol{\mu}\right)\right]^{\prime}} \\
\vdots \\
{\left[\Phi(\mathrm{L})\left(\Delta \boldsymbol{y}_{T}-\boldsymbol{\mu}\right)\right]^{\prime}}
\end{array}\right], \quad \boldsymbol{E}:=\left[\begin{array}{c}
-\boldsymbol{e}_{p}^{\prime} \\
\vdots \\
-\boldsymbol{e}_{T-1}^{\prime}
\end{array}\right]
$$

Then we have a normal linear model for $\boldsymbol{W}$ given $\boldsymbol{E}$ such that

$$
\begin{aligned}
\boldsymbol{W} & =\boldsymbol{E} \Lambda^{\prime}+\boldsymbol{U} \\
\boldsymbol{U} & \sim \mathrm{N}_{(T-p) \times N}\left(\mathbf{0}_{(T-p) \times N} ; \boldsymbol{I}_{T-p}, \boldsymbol{P}^{-1}\right)
\end{aligned}
$$

or

$$
\begin{aligned}
\boldsymbol{W}^{\prime} & =\Lambda \boldsymbol{E}^{\prime}+\boldsymbol{U}^{\prime} \\
\boldsymbol{U}^{\prime} & \sim \mathrm{N}_{N \times(T-p)}\left(\mathbf{0}_{N \times(T-p)} ; \boldsymbol{P}^{-1}, \boldsymbol{I}_{T-p}\right)
\end{aligned}
$$

Let $\lambda:=\operatorname{vec}(\boldsymbol{\Lambda})$. Then we have a normal linear model for $\operatorname{vec}\left(\boldsymbol{W}^{\prime}\right)$ such that

$$
\begin{aligned}
\operatorname{vec}\left(\boldsymbol{W}^{\prime}\right) & =\left(\boldsymbol{E} \otimes \boldsymbol{I}_{N}\right) \lambda+\operatorname{vec}\left(\boldsymbol{U}^{\prime}\right) \\
\operatorname{vec}\left(\boldsymbol{U}^{\prime}\right) & \sim \mathrm{N}_{N(T-p)}\left(\mathbf{0}_{N(T-p)}, \boldsymbol{I}_{T-p} \otimes \boldsymbol{P}^{-1}\right)
\end{aligned}
$$

Theorem 4. Suppose that

$$
\lambda \mid \boldsymbol{\psi}, \boldsymbol{\Phi}, \boldsymbol{P}, \Gamma \sim \mathrm{N}_{N r}\left(\mathbf{0}_{N r}, \boldsymbol{U}_{0}^{-1}\right)
$$

where $\boldsymbol{U}_{0}:=\boldsymbol{I}_{r} \otimes \eta_{0} \boldsymbol{G}_{0}$. Then

$$
\lambda \mid \boldsymbol{\Psi}, \boldsymbol{\Phi}, \boldsymbol{P}, \Gamma, \boldsymbol{W}, \boldsymbol{E} \sim \mathrm{N}_{N r}\left(\lambda_{1}, \boldsymbol{U}_{1}^{-1}\right)
$$

where

$$
\begin{aligned}
& \boldsymbol{U}_{1}=\boldsymbol{E}^{\prime} \boldsymbol{E} \otimes \boldsymbol{P}+\boldsymbol{U}_{0} \\
& \lambda_{1}=\boldsymbol{U}_{1}^{-1} \operatorname{vec}\left(\boldsymbol{P} \boldsymbol{W}^{\prime} \boldsymbol{E}\right)
\end{aligned}
$$

Proof. Let $\boldsymbol{\Lambda}_{\mathrm{OLS}}:=\boldsymbol{W}^{\prime} \boldsymbol{E}\left(\boldsymbol{E}^{\prime} \boldsymbol{E}\right)^{-1}$ and $\lambda_{\mathrm{OLS}}:=\operatorname{vec}\left(\boldsymbol{\Lambda}_{\mathrm{OLS}}\right)$. By Lemma 1,

$$
\begin{aligned}
\boldsymbol{U}_{1} & :=\left(\boldsymbol{E} \otimes \boldsymbol{I}_{N}\right)^{\prime}\left(\boldsymbol{I}_{T-p} \otimes \boldsymbol{P}\right)\left(\boldsymbol{E} \otimes \boldsymbol{I}_{N}\right)+\boldsymbol{U}_{0} \\
& =\boldsymbol{E}^{\prime} \boldsymbol{E} \otimes \boldsymbol{P}+\boldsymbol{U}_{0} \\
\lambda_{1} & :=\boldsymbol{U}_{1}^{-1}\left(\boldsymbol{E}^{\prime} \boldsymbol{E} \otimes \boldsymbol{P}\right) \lambda_{\mathrm{OLS}}
\end{aligned}
$$

where

$$
\begin{aligned}
\left(\boldsymbol{E}^{\prime} \boldsymbol{E} \otimes \boldsymbol{P}\right) \lambda_{\mathrm{OLS}} & =\left(\boldsymbol{E}^{\prime} \boldsymbol{E} \otimes \boldsymbol{P}\right) \operatorname{vec}\left(\boldsymbol{W}^{\prime} \boldsymbol{E}\left(\boldsymbol{E}^{\prime} \boldsymbol{E}\right)^{-1}\right) \\
& =\left(\boldsymbol{E}^{\prime} \boldsymbol{E} \otimes \boldsymbol{P}\right)\left[\left(\boldsymbol{E}^{\prime} \boldsymbol{E}\right)^{-1} \otimes \boldsymbol{W}^{\prime}\right] \operatorname{vec}(\boldsymbol{E}) \\
& =\left(\boldsymbol{I}_{r} \otimes \boldsymbol{P} \boldsymbol{W}^{\prime}\right) \operatorname{vec}(\boldsymbol{E})
\end{aligned}
$$




$$
=\operatorname{vec}\left(\boldsymbol{P} \boldsymbol{W}^{\prime} \boldsymbol{E}\right)
$$

\section{A.5 Cointegrating matrix}

Write the VECM as for all $t$,

$$
\Phi(\mathrm{L})\left(\Delta \boldsymbol{y}_{t}-\boldsymbol{\mu}\right)-\Lambda \boldsymbol{\beta}=-\Lambda \Gamma^{\prime}\left[\boldsymbol{y}_{t-1}-\boldsymbol{\mu}(t-1)\right]+\boldsymbol{u}_{t}
$$

Let

$$
\boldsymbol{W}_{*}:=\left[\begin{array}{c}
{\left[\Phi(\mathrm{L})\left(\Delta \boldsymbol{y}_{p+1}-\boldsymbol{\mu}\right)-\Lambda \boldsymbol{\beta}\right]^{\prime}} \\
\vdots \\
{\left[\Phi(\mathrm{L})\left(\Delta \boldsymbol{y}_{T}-\boldsymbol{\mu}\right)-\Lambda \boldsymbol{\beta}\right]^{\prime}}
\end{array}\right], \quad \boldsymbol{Z}_{*}:=\left[\begin{array}{c}
-\left(\boldsymbol{y}_{p}-p \boldsymbol{\mu}\right)^{\prime} \\
\vdots \\
-\left[\boldsymbol{y}_{T-1}-(T-1) \boldsymbol{\mu}\right]^{\prime}
\end{array}\right]
$$

Then we have a normal linear model for $\boldsymbol{W}_{*}$ given $\boldsymbol{Z}_{*}$ such that

$$
\begin{aligned}
\boldsymbol{W}_{*} & =\boldsymbol{Z}_{*} \Gamma \Lambda^{\prime}+\boldsymbol{U} \\
\boldsymbol{U} & \sim \mathrm{N}_{(T-p) \times N}\left(\mathbf{0}_{(T-p) \times N} ; \boldsymbol{I}_{T-p}, \boldsymbol{P}^{-1}\right)
\end{aligned}
$$

Let $\boldsymbol{\gamma}:=\operatorname{vec}(\boldsymbol{\Gamma})$. Then we have a normal linear model for $\operatorname{vec}\left(\boldsymbol{W}_{*}\right)$ such that

$$
\begin{aligned}
\operatorname{vec}\left(\boldsymbol{W}_{*}\right) & =\left(\Lambda \otimes \boldsymbol{Z}_{*}\right) \boldsymbol{\gamma}+\operatorname{vec}(\boldsymbol{U}) \\
\operatorname{vec}(\boldsymbol{U}) & \sim \mathrm{N}_{N(T-p)}\left(\mathbf{0}_{N(T-p)}, \boldsymbol{P}^{-1} \otimes \boldsymbol{I}_{T-p}\right)
\end{aligned}
$$

Theorem 5. Suppose that

$$
\gamma \mid \boldsymbol{\psi}, \boldsymbol{\Phi}, \boldsymbol{P}, \Lambda \sim \mathrm{N}_{N r}\left(\mathbf{0}_{N r}, \boldsymbol{V}_{0}^{-1}\right)
$$

where $\boldsymbol{V}_{0}:=\boldsymbol{I}_{r} \otimes \boldsymbol{H}\left(\tau_{0}\right)$. Then

$$
\boldsymbol{\gamma} \mid \boldsymbol{\psi}, \boldsymbol{\Phi}, \boldsymbol{P}, \Lambda, \boldsymbol{W}_{*}, \boldsymbol{Z}_{*} \sim \mathrm{N}_{N r}\left(\boldsymbol{\gamma}_{1}, \boldsymbol{V}_{1}^{-1}\right)
$$

where

$$
\begin{aligned}
& \boldsymbol{V}_{1}=\Lambda^{\prime} \boldsymbol{P} \Lambda \otimes \boldsymbol{Z}_{*}^{\prime} \boldsymbol{Z}_{*}+\boldsymbol{V}_{0} \\
& \boldsymbol{\gamma}_{1}=\boldsymbol{V}_{1}^{-1} \operatorname{vec}\left(\boldsymbol{Z}_{*}^{\prime} \boldsymbol{W}_{*} \boldsymbol{P} \Lambda\right)
\end{aligned}
$$

Proof. Let $\gamma_{\mathrm{GLS}}$ be the GLS estimator of $\gamma$, i.e.,

$$
\begin{aligned}
\boldsymbol{\gamma}_{\mathrm{GLS}} & =\left[\left(\Lambda \otimes \boldsymbol{Z}_{*}\right)^{\prime}\left(\boldsymbol{P} \otimes \boldsymbol{I}_{T-p}\right)\left(\Lambda \otimes \boldsymbol{Z}_{*}\right)\right]^{-1}\left(\Lambda \otimes \boldsymbol{Z}_{*}\right)^{\prime}\left(\boldsymbol{P} \otimes \boldsymbol{I}_{T-p}\right) \operatorname{vec}\left(\boldsymbol{W}_{*}\right) \\
& =\left(\Lambda^{\prime} \boldsymbol{P} \Lambda \otimes \boldsymbol{Z}_{*}^{\prime} \boldsymbol{Z}_{*}\right)^{-1}\left(\Lambda^{\prime} \boldsymbol{P} \otimes \boldsymbol{Z}_{*}^{\prime}\right) \operatorname{vec}\left(\boldsymbol{W}_{*}\right) \\
& =\left(\Lambda^{\prime} \boldsymbol{P} \Lambda \otimes \boldsymbol{Z}_{*}^{\prime} \boldsymbol{Z}_{*}\right)^{-1} \operatorname{vec}\left(\boldsymbol{Z}_{*}^{\prime} \boldsymbol{W}_{*} \boldsymbol{P} \Lambda\right)
\end{aligned}
$$

By Lemma 1,

$$
\begin{aligned}
\boldsymbol{V}_{1} & :=\left(\Lambda \otimes Z_{*}\right)^{\prime}\left(\boldsymbol{P} \otimes \boldsymbol{I}_{T-p}\right)\left(\Lambda \otimes \boldsymbol{Z}_{*}\right)+\boldsymbol{V}_{0} \\
& =\Lambda^{\prime} \boldsymbol{P} \Lambda \otimes \boldsymbol{Z}_{*}^{\prime} \boldsymbol{Z}_{*}+\boldsymbol{V}_{0} \\
\boldsymbol{\gamma}_{1} & :=\boldsymbol{V}_{1}^{-1}\left(\Lambda^{\prime} \boldsymbol{P} \Lambda \otimes \boldsymbol{Z}_{*}^{\prime} \boldsymbol{Z}_{*}\right) \boldsymbol{\gamma}_{\mathrm{GLS}} \\
& =\boldsymbol{V}_{1}^{-1} \operatorname{vec}\left(\boldsymbol{Z}_{*}^{\prime} \boldsymbol{W}_{*} \boldsymbol{P} \Lambda\right)
\end{aligned}
$$




\section{A.6 Tightness hyperparameter}

We have

$$
\begin{aligned}
p(v \mid \psi, \Phi, \boldsymbol{P}, \Lambda, \Gamma, \boldsymbol{Y}) & \propto p(\boldsymbol{Y} \mid \boldsymbol{\Psi}, \boldsymbol{\Phi}, \boldsymbol{P}, \Lambda, \Gamma, v) p(\boldsymbol{\Psi} \mid \Phi, \boldsymbol{P}, \Lambda, \Gamma, v) p(\Lambda, \Gamma \mid \Phi, \boldsymbol{P}, v) p(\Phi, \boldsymbol{P} \mid v) p(v) \\
& =p(\boldsymbol{Y} \mid \boldsymbol{\Psi}, \boldsymbol{\Phi}, \boldsymbol{P}, \Lambda, \Gamma) p(\boldsymbol{\psi} \mid \Phi, \boldsymbol{P}, \Lambda, \Gamma) p(\Lambda, \Gamma \mid \Phi, \boldsymbol{P}) p(\boldsymbol{\Phi}, \boldsymbol{P} \mid v) p(v) \\
& \propto p(\Phi, \boldsymbol{P} \mid v) p(v)
\end{aligned}
$$

Thus $p(\nu \mid \boldsymbol{\psi}, \boldsymbol{\Phi}, \boldsymbol{P}, \boldsymbol{\Lambda}, \boldsymbol{\Gamma}, \boldsymbol{Y})=p(\nu \mid \boldsymbol{\Phi}, \boldsymbol{P})$.

Theorem 6. Suppose that

$$
\nu \sim \operatorname{Gam}\left(\frac{A_{0}}{2}, \frac{B_{0}}{2}\right)
$$

Then

$$
\nu \mid \Phi, \boldsymbol{P} \sim \operatorname{Gam}\left(\frac{A_{1}}{2}, \frac{B_{1}}{2}\right)
$$

where

$$
\begin{aligned}
& A_{1}:=\mathrm{p} N^{2}+A_{0} \\
& B_{1}:=\operatorname{tr}\left(\boldsymbol{P}\left(\boldsymbol{\Phi}-\boldsymbol{M}_{0}\right) \boldsymbol{D}_{0}\left(\boldsymbol{\Phi}-\boldsymbol{M}_{0}\right)^{\prime}\right)+B_{0}
\end{aligned}
$$

Proof. We have

$$
\begin{aligned}
p(v \mid \Phi, \boldsymbol{P}) & \propto p(\boldsymbol{\Phi}, \boldsymbol{P}, v) \\
& =p(\Phi \mid \boldsymbol{P}, v) p(\boldsymbol{P}) p(v) \\
& \propto p(\boldsymbol{\Phi} \mid \boldsymbol{P}, v) p(v)
\end{aligned}
$$

where $^{25}$

$$
\begin{aligned}
p(\Phi \mid \boldsymbol{P}, v) & =\frac{\operatorname{etr}\left(-\boldsymbol{P}\left(\boldsymbol{\Phi}-\boldsymbol{M}_{0}\right) v \boldsymbol{D}_{0}\left(\boldsymbol{\Phi}-\boldsymbol{M}_{0}\right)^{\prime} / 2\right)}{(2 \pi)^{p N^{2} / 2} \operatorname{det}\left(v \boldsymbol{D}_{0}\right)^{-N / 2} \operatorname{det}(\boldsymbol{P})^{-p N / 2}} \\
p(v) & =\frac{v^{A_{0} / 2-1} / \mathrm{e}^{\left(B_{0} / 2\right) v}}{\Gamma\left(A_{0} / 2\right)\left(B_{0} / 2\right)^{-A_{0} / 2}}
\end{aligned}
$$

Hence

$$
\begin{aligned}
p(v \mid \boldsymbol{\Phi}, \boldsymbol{P}) & \propto v^{p N^{2} / 2} \operatorname{etr}\left(-\frac{\boldsymbol{P}\left(\boldsymbol{\Phi}-\boldsymbol{M}_{0}\right) \nu \boldsymbol{D}_{0}\left(\boldsymbol{\Phi}-\boldsymbol{M}_{0}\right)^{\prime}}{2}\right) \frac{v^{A_{0} / 2-1}}{\mathrm{e}^{\left(B_{0} / 2\right) v}} \\
& =\frac{v^{\left(p N^{2}+A_{0}\right) / 2-1}}{\mathrm{e}^{\left\{\left[\operatorname{tr}\left(\boldsymbol{P}\left(\boldsymbol{\Phi}-\boldsymbol{M}_{0}\right) \boldsymbol{D}_{0}\left(\boldsymbol{\Phi}-\boldsymbol{M}_{0}\right)^{\prime}\right)+B_{0}\right] / 2\right\} v}}
\end{aligned}
$$

\section{References}

Abadir, K. M., and J. R. Magnus. 2002. "Notation in Econometrics: A Proposal for a Standard." The Econometrics Journal 5: 76-90.

Bańbura, M., D. Giannone, and L. Reichlin. 2010. “Large Bayesian Vector Auto Regressions.” Journal of Applied Econometrics 25: 71-92.

25 See Gupta and Nagar (1999) on the pdf of a matrix normal distribution. 
Beveridge, S., and C. R. Nelson. 1981. "A New Approach to Decomposition of Economic Time Series into Permanent and Transitory Components with Particular Attention to Measurement of the 'Business Cycle'." Journal of Monetary Economics 7: 151-74.

Brzoza-Brzezina, M., and J. Kotłowski. 2014. “Measuring the Natural Yield Curve.” Applied Economics 46: 2052-65.

Chan, J. C. C., T. E. Clark, and G. Koop. 2018. “A New Model of Inflation, Trend Inflation, and Long-Run Inflation Expectations.” Journal of Money, Credit, and Banking 50: 5-53.

Chikuse, Y. 1990. “The Matrix Angular Central Gaussian Distribution.” Journal of Multivariate Analysis 33: $265-74$.

Chikuse, Y. 2003. Statistics on Special Manifolds. New York: Springer.

Cochrane, J. H. 1994. "Permanent and Transitory Components of GNP and Stock Prices." Quarterly Journal of Economics 109: 241-65.

Cogley, T., and T. J. Sargent. 2002. “Evolving Post-World War II U.S. Inflation Dynamics.” NBER Macroeconomics Annual 16: 331-73.

Cogley, T., and T. J. Sargent. 2005. "Drifts and Volatilities: Monetary Policies and Outcomes in the Post WWII US." Review of Economic Dynamics 8: 262-302.

Cogley, T., S. Morozov, and T. J. Sargent. 2005. "Bayesian Fan Charts for U.K. Inflation: Forecasting and Sources of Uncertainty in an Evolving Monetary System." Journal of Economic Dynamics and Control 29: 1893-925.

Cogley, T., G. E. Primiceri, and T. J. Sargent. 2010. “Inflation-Gap Persistence in the US.” American Economic Journal: Macroeconomics 2: 43-69.

Crump, R., S. Eusepi, M. Giannoni, and A. Şahin. 2019. “A Unified Approach to Measuring u*.” In Brookings Papers on Economic Activity 2019, 143-214.

Del Negro, M., D. Giannone, M. P. Giannoni, and A. Tambalotti. 2017. "Safety, Liquidity, and the Natural Rate of Interest." In Brookings Papers on Economic Activity 2017, 235-94.

Drèze, J. H., and J.-F. Richard. 1983. "Bayesian Analysis of Simultaneous Equation Systems.” In Handbook of Econometrics, Vol. 1, edited by Z. Griliches, and M. D. Intriligator, chapter 9, 517-98. Amsterdam: North-Holland.

Evans, G. W. 1989a. “A Measure of the U.S. Output Gap.” Economics Letters 29: 285-9.

Evans, G. W. 1989b. “Output and Unemployment Dynamics in the United States: 1950-1985.” Journal of Applied Econometrics 4: 213-37.

Evans, G. W., and L. Reichlin. 1994. “Information, Forecasts, and Measurement of the Business Cycle.” Journal of Monetary Economics 33: 233-54.

Faust, J., and J. H. Wright. 2013. "Forecasting Inflation.” In Handbook of Economic Forecasting, Vol. 2A, edited by G. Elliott, and A. Timmermann, chapter 1, 2-56. Amsterdam: North-Holland.

Fisher, L. A., H.-S. Huh, and A. R. Pagan. 2016. "Econometric Methods for Modelling Systems with a Mixture of I(1) and I(0) Variables." Journal of Applied Econometrics 31: 892-911.

Galí, J. 2015. Monetary Policy, Inflation, and the Business Cycle, 2nd ed. Princeton, NJ: Princeton University Press.

Garratt, A., D. Robertson, and S. Wright. 2006. "Permanent vs Transitory Components and Economic Fundamentals." Journal of Applied Econometrics 21: 521-42.

Gelman, A., J. B. Carlin, H. S. Stern, D. B. Dunson, A. Vehtari, and D. B. Rubin. 2014. Bayesian Data Analysis, 3rd ed. Boca Raton, FL: CRC Press.

Giannone, D., M. Lenza, and G. E. Primiceri. 2015. "Prior Selection for Vector Autoregressions." The Review of Economics and Statistics 97: 436-51.

Glick, R. 2020. "r* and the Global Economy.” Journal of International Money and Finance 102: 102105.

Granger, C. W. J., and T. H. Lee. 1989. "Investigation of Production, Sales and Inventory Relationships Using Multicointegration and Non-symmetric Error Correction Models." Journal of Applied Econometrics 4: S145-59.

Granger, C. W. J., and T. H. Lee. 1990. “Multicointegration.” Advances in Econometrics 8: 71-84.

Gregoir, S., and G. Laroque. 1993. "Multivariate Time Series: A Polynomial Error Correction Representation Theorem." Econometric Theory 9: 329-42.

Gregoir, S., and G. Laroque. 1994. "Polynomial Cointegration: Estimation and Test.” Journal of Econometrics 63: $183-214$.

Gupta, A. K., and D. K. Nagar. 1999. Matrix Variate Distributions. Boca Raton, FL: CRC Press.

Hamilton, J. D., E. S. Harris, J. Hatzius, and K. D. West. 2016. “The Equilibrium Real Funds Rate: Past, Present, and Future.” IMF Economic Review 64: 660-707.

Holston, K., T. Laubach, and J. C. Williams. 2017. “Measuring the Natural Rate of Interest: International Trends and Determinants.” Journal of International Economics 108: S59-75.

Hwu, S.-T., and C.-J. Kim. 2019. "Estimating Trend Inflation Based on Unobserved Components Model: Is it Correlated with the Inflation Gap?” Journal of Money, Credit, and Banking 51: 2305-19.

Imakubo, K., H. Kojima, and J. Nakajima. 2018. “The Natural Yield Curve: Its Concept and Measurement.” Empirical Economics 55: 551-72.

Johansen, S. 1995. “A Statistical Analysis of Cointegration for I(2) Variables.” Econometric Theory 11: 25-59. 
Kadiyala, K. R., and S. Karlsson. 1997. “Numerical Methods for Estimation and Inference in Bayesian VAR-Models.” Journal of Applied Econometrics 12: 99-132.

Kamber, G., J. Morley, and B. Wong. 2018. "Intuitive and Reliable Estimates of the Output Gap from a Beveridge-Nelson Filter." The Review of Economics and Statistics 100: 550-66.

Kiley, M. T. 2013. “Output Gaps.” Journal of Macroeconomics 37: 1-18.

Kilian, L., and H. Lütkepohl. 2017. Structural Vector Autoregressive Analysis. Cambridge, UK: Cambridge University Press.

King, R., C. Plosser, J. Stock, and M. Watson. 1991. "Stochastic Trends and Economic Fluctuations." The American Economic Review 81: 819-40.

Koop, G. 2003. Bayesian Econometrics. Chichester: John Wiley \& Sons.

Koop, G., R. León-González, and R. W. Strachan. 2008. "Bayesian Inference in a Cointegrating Panel Data Model.” Advances in Econometrics 23: 433-69.

Koop, G., R. León-González, and R. W. Strachan. 2010. "Efficient Posterior Simulation for Cointegrated Models with Priors on the Cointegration Space.” Econometric Reviews 29: 224-42.

Laubach, T., and J. C. Williams. 2003. "Measuring the Natural Rate of Interest." The Review of Economics and Statistics 85: $1063-70$.

Laubach, T., and J. C. Williams. 2016. "Measuring the Natural Rate of Interest Redux.” Business Economics 51: 57-67.

Lewis, K. F., and F. Vazquez-Grande. 2019. "Measuring the Natural Rate of Interest: A Note on Transitory Shocks.” Journal of Applied Econometrics 34: 425-36.

Lunsford, K. G., and K. D. West. 2019. "Some Evidence on Secular Drivers of US Safe Real Rates.” American Economic Journal: Macroeconomics 11: 113-39.

Morley, J. 2002. “A State-Space Approach to Calculating the Beveridge-Nelson Decomposition.” Economics Letters 75: $123-7$. Morley, J. 2011. "The Two Interpretations of the Beveridge-Nelson Decomposition.” Macroeconomic Dynamics 15: 419-39.

Morley, J., and B. Wong. 2020. "Estimating and Accounting for the Output Gap with Large Bayesian Vector Autoregressions." Journal of Applied Econometrics 35: 1-18.

Morley, J., C. R. Nelson, and E. Zivot. 2003. "Why Are the Beveridge-Nelson and Unobserved-Components Decompositions of GDP So Different?" The Review of Economics and Statistics 85: 235-43.

Morley, J., J. Piger, and R. Rasche. 2015. “Inflation in the G7: Mind the Gap(s)?” Macroeconomic Dynamics 19: 883-912.

Murasawa, Y. 2014. “Measuring the Natural Rates, Gaps, and Deviation Cycles.” Empirical Economics 47: 495-522.

Murasawa, Y. 2015. "The Multivariate Beveridge-Nelson Decomposition with I(1) and I(2) Series." Economics Letters 137: 157-62.

Murasawa, Y. 2016. “The Beveridge-Nelson Decomposition of Mixed-Frequency Series.” Empirical Economics 51: $1415-41$.

Nelson, C. R. 2008. "The Beveridge-Nelson Decomposition in Retrospect and Prospect." Journal of Econometrics 146: 202-6.

Newbold, P., and D. Vougas. 1996. "Beveridge-Nelson-Type Trends for I(2) and Some Seasonal Models." Journal of Time Series Analysis 17: 151-69.

Oh, K. H., and E. Zivot. 2006. "The Clark Model with Correlated Components." Available at SSRN.

Oh, K. H., E. Zivot, and D. Creal. 2008. "The Relationship between the Beveridge-Nelson Decomposition and Other Permanent-Transitory Decompositions that Are Popular in Economics." Journal of Econometrics 146: 207-19.

Perron, P., and Z. Qu. 2007. “A Simple Modification to Improve the Finite Sample Properties of Ng and Perron's Unit Root Tests.” Economics Letters 94: 12-9.

Phelps, E. S. 1995. "The Origins and Further Development of the Natural Rate of Unemployment." In The Natural Rate of Unemployment: Reflections on 25 Years of the Hypothesis, edited by R. Cross, chapter 2, 15-31. Cambridge, UK: Cambridge University Press.

R Core Team. 2021. R: A Language and Environment for Statistical Computing. Vienna, Austria.

Robert, C. P., and G. Casella. 2009. Introducing Monte Carlo Methods with R. New York: Springer.

Rotemberg, J. J., and M. Woodford. 1996. "Real-Business-Cycle Models and the Forecastable Movements in Output, Hours, and Consumption." The American Economic Review 86: 71-89.

Strachan, R. W., and B. Inder. 2004. "Bayesian Analysis of the Error Correction Model." Journal of Econometrics 123: 307-25.

Verdinelli, I., and L. Wasserman. 1995. "Computing Bayes Factors Using a Generalization of the Savage-Dickey Density Ratio." Journal of the American Statistical Association 90: 614-18.

Villani, M. 2009. "Steady-State Priors for Vector Autoregressions." Journal of Applied Econometrics 24: 630-50.

Wagenmakers, E.-J., T. Lodewyckx, H. Kuriyal, and R. Grasman. 2010. "Bayesian Hypothesis Testing for Psychologists: A Tutorial on the Savage-Dickey Method.” Cognitive Psychology 60: 158-89.

Woodford, M. 2003. Interest and Prices. Princeton, NJ: Princeton University Press.

Supplementary Material: The Code Ocean capsule for this work is available at https://doi.org/10.24433/C0.7416251.v1. 